\title{
Remote Sensing of Shallow Coastal Benthic Substrates: In situ Spectra and Mapping of Eelgrass (Zostera marina) in the Gulf Islands National Park Reserve of Canada
}

\author{
Jennifer D. O’Neill ${ }^{1}{ }^{*}$, Maycira Costa ${ }^{1}$ and Tara Sharma ${ }^{2}$
}

1 Spectral Lab, Department of Geography, University of Victoria, P.O. Box 3060, STN CSC, Victoria, BC V8W 3R4, Canada; E-Mail: maycira@uvic.ca

2 Parks Canada Office at Gulf Islands, National Park Reserve of Canada, 2220 Harbour Road, Sidney, BC V8L 2P6, Canada; E-Mail: Tara.Sharma@pc.gc.ca

* Author to whom correspondence should be addressed; E-Mail: joneill@uvic.ca;

Tel.: +1-250-472-5223; Fax: +1-250-721-6216.

Received: 28 February 2011; in revised form: 5 May 2011 / Accepted: 6 May 2011 /

Published: 16 May 2011

\begin{abstract}
Eelgrass (Zostera marina) is a keystone component of inter- and sub-tidal ecosystems. However, anthropogenic pressures have caused its populations to decline worldwide. Delineation and continuous monitoring of eelgrass distribution is an integral part of understanding these pressures and providing effective coastal ecosystem management. A proposed tool for such spatial monitoring is remote imagery, which can cost- and time-effectively cover large and inaccessible areas frequently. However, to effectively apply this technology, an understanding is required of the spectral behavior of eelgrass and its associated substrates. In this study, in situ hyperspectral measurements were used to define key spectral variables that provide the greatest spectral separation between Z. marina and associated submerged substrates. For eelgrass classification of an in situ above water reflectance dataset, the selected variables were: slope 500-530 nm, first derivatives (R') at $566 \mathrm{~nm}, 580 \mathrm{~nm}$, and $602 \mathrm{~nm}$, yielding 98\% overall accuracy. When the in situ reflectance dataset was water-corrected, the selected variables were: 566:600 and 566:710, yielding 97\% overall accuracy. The depth constraint for eelgrass identification with the field spectrometer was 5.0 to $6.0 \mathrm{~m}$ on average, with a range of 3.0 to $15.0 \mathrm{~m}$ depending on the characteristics of the water column. A case study involving benthic classification of hyperspectral airborne imagery showed the major advantage of the variable selection was meeting the sample size requirements of the more statistically complex Maximum
\end{abstract}


Likelihood classifier. Results of this classifier yielded eelgrass classification accuracy of over $85 \%$. The depth limit of eelgrass spectral detection for the AISA sensor was $5.5 \mathrm{~m}$.

Keywords: eelgrass; seagrass; remote sensing; hyperspectral; feature selection

\section{Introduction}

Eelgrass (Zostera marina) is an important component of inter- and sub-tidal ecosystems and is widely recognized for its ecological and conservation value [1,2]. Among its many ecological functions are those of providing physical shoreline stability [3] and of mediating biochemical balance within the immediate and broader ecosystem [1,4]. For instance, eelgrass may be responsible for up to $15 \%$ of the total organic carbon stored in marine ecosystems by way of burial and exportation of detritus to neighboring ecosystems [5]. Eelgrass also provides a fundamental nursery ground and food source for a variety of marine organisms, from complex macroinvertebrate assemblages to several species of commercially important fish, notably out migrating juvenile salmon (Onchorhynchus spp.) and Pacific herring (Clupea harengus) [6-8]. Accordingly, eelgrass has been identified as an exceptionally important resource to sustainable commercial fisheries [9]. Its keystone importance and high sensitivity to changes in water quality have established it worldwide as an indicator of coastal ecosystem health and an early harbinger of environmental change [6].

Eelgrass populations have experienced worldwide decline. An estimated 2-5\% of seagrass ecosystems are lost annually due to anthropogenic pressures [10]. The loss has been attributed to two major forces: (1) the direct pressures of a growing coastal human population, such as shoreline development [10,11] and vessel anchoring [12]; and (2) the indirect pressure of activities that diminish the available photosynthetically active radiation through sedimentation, nutrient loading, and eutrophication [11]. These activities include intense aquaculture [4,13,14], upland development and agriculture [15], and increased pollution levels [16,17]. Eelgrass loss is predicted to accelerate in response to climate change $[10,18]$ and growing human pressure on the coastal zone [10].

Baseline knowledge and continued monitoring of temporal-spatial eelgrass distribution is exceedingly important in mitigating additional loss, as it allows separation of anthropogenic disturbances from natural trends and identification of suitable areas for protection and rehabilitation [10,19,20]. Mapping of eelgrass and other benthic substrates has traditionally been accomplished by boat- and land-based surveys, which are limited by accessibility, time, and cost [19,21]. A proposed alternative method is remote imagery, which can cost- and time-effectively cover large and inaccessible areas nearly instantly and frequently [19]. The effective application of this technology, however, requires a firm understanding of the spectral behavior of eelgrass and associated substrates on the west coast of British Columbia. Submerged eelgrass can only be detected by a remote sensor if: (1) eelgrass spectral properties are distinct from those of surrounding cover types (sand, macroalgae, epiphytes, detritus, etc.); (2) the unique spectral characteristics can be separated from the spectral influence of the atmosphere and water column; (3) the spectral resolution of the sensor is adequate to resolve the 
unique spectral characteristics; and (4) the spatial resolution of the sensor is adequate to capture the spatial patterns (i.e., patchiness) of the eelgrass meadow [22].

The success of requirement (1) can be influenced by the properties of water column. With increasing depth, eelgrass and surrounding substrate become less spectrally separable, as the optical properties of the water column constituents tend to dominate the signal $[19,20]$. The degree of this dominance is wavelength and constituent dependent. In coastal waters (Case 2 waters), three major optical constituents cause wavelength dependent attenuation of light: chromophoric dissolved organic material (CDOM), phytoplankton photosynthetic pigment chlorophyll- $a$ (Chl- $a$ ), and total suspended matter (TSM), which can be separated in organic and inorganic fractions. Generally, CDOM and Chl- $a$ reduce the reflectance signal by absorbing light in the blue and red (Chl- $a$ only) spectral ranges, while TSM increases the reflectance signal in the red region and shifts the green peak to longer wavelengths $[23,24]$. The attenuation caused by each of these water constituents acts to diminish available light with increasing depth, particularly in blue and red ranges of the spectrum. Further, the success of requirement (1) can also be affected by epiphytic loading, which can remarkably change the reflectance of eelgrass. Studies have shown that heavy epiphyte loads can absorb up to $63 \%$ of incident light in the peak chlorophyll absorption bands, leading to greater reflectance slopes at $440 \mathrm{~nm}$ and $680 \mathrm{~nm}$ than at $550 \mathrm{~nm}$ [25]. Reflectance in the 575-630 nm region is markedly increased [26] while green light is physically blocked by non-photosynthetic material accumulation [25] and absorbed by non-chlorophyte epiphytes [27]. These effects lead to a flattening of the eelgrass spectral signature and increased variability in green reflectance values [26,28]. Additionally, two unique features are produced by epiphyte chlorophyll- $a$ and $-c$ a reflectance peak at $590 \mathrm{~nm}$ [26] and a small absorption feature at $632 \mathrm{~nm}[29,30]$.

The characteristics of the remote sensor have an additional impact on the detectability of eelgrass, as higher spatial and spectral resolution offer dicernability of greater spatial and spectral detail and a greater understanding of the key optical differences between substrates. Greater resolution however, comes with the expense of increased processing time and reduced accuracy by way of large data volumes and high data redundancy. Data reduction methods can be used to address these volume and redundancy issues by removing unnecessary information and retaining only spectral variables offering the greatest spectral distinction between cover classes [31].

In this light, the goal of this study was two-fold: (1) to use in situ hyperspectral measurements to identify bands or bands indices (hereafter called spectral variables) suitable for spectral separation of eelgrass from other substrates; and (2) to test the identified spectral variables in benthic classification of an image. The questions asked of the dataset were:

1. Can submerged eelgrass be spectrally distinguished from other submerged substrates? If so, what spectral variables (bands and/or band slopes/ratios) offer the most accurate separation among substrates with the least redundancy?

2. How effective are these spectral variables for detecting eelgrass in a hyperspectral airborne image?

3. What is the wavelength-dependent depth limit of eelgrass spectral detection in situ and in the image? 


\section{Methods}

\subsection{Study Area}

This research took place at Sidney Spit, a $1.78 \mathrm{~km}^{2}$ protected marine area on the northwestern extreme of Sidney Island, British Columbia, Canada, which encompasses a $1.8 \mathrm{~km}$ long sand spit and shallow lagoon (Figure 1). The area is protected within the Gulf Islands National Park Reserve of Canada (GINPRC) [32]. The major submerged substrates present at the site were eelgrass (Zostera marina), green algae (Ulva fenestrata, Enteromorpha spp., and filamentous green algae), and sand. The halophyte Salicornia virginica (sea asparagus) was found in large homogeneous stands in the extreme south of the lagoon, while brown algae (Fucus spp., Sargassum muticum, and Laminaria saccharina) were present but were not found at high areal coverage $\left(<1 \mathrm{~m}^{2}\right.$ patches $)$ at the time of sampling.

Figure 1. Sidney Spit, Sidney Island, British Columbia is part of the Gulf Islands National Park Reserve of Canada (GINPRC). Pale red area represents Marine protected area within the park; dark red represents Marine Extension area (Modified from [32]).

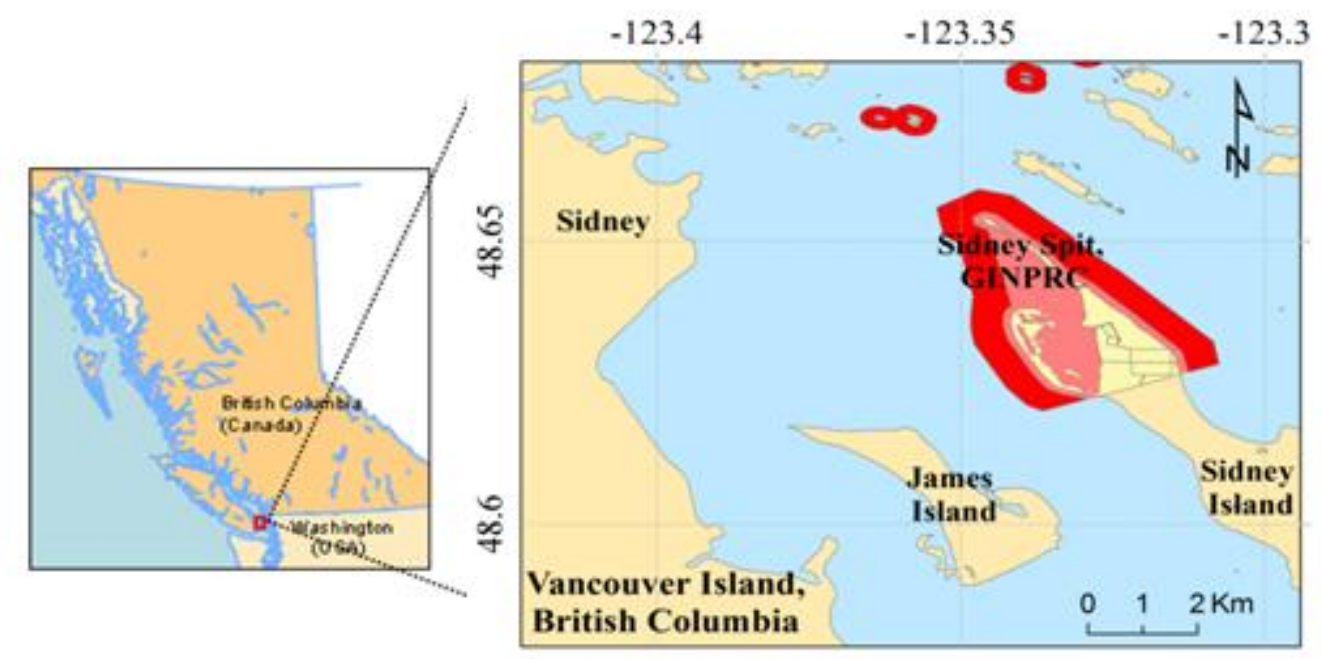

The waters immediately east and west of the sand spit were underlain by shallow sloping sandy substrate and fringing beds of intertidal Z. marina. Subtidal Z. marina inhabited sandbars approximately $500 \mathrm{~m}$ west of the spit. A shallow lagoon located southwest of Sidney Spit and bordered on its west side by Hook Spit contained a large and very well protected eelgrass bed that was entirely exposed during lowest tide events. Previous assessment by Parks Canada reports the following average metrics for eelgrass in the lagoon: density $=300$ shoots $/ \mathrm{m}^{2}$, biomass $=198.8 \mathrm{~g} / \mathrm{m}^{2}$, and total eelgrass meadow extent estimated from orthophotos $=183,000 \mathrm{~m}^{2}$ [33]. Studies have revealed that boaters frequently anchor in the eelgrass beds [34].

The water was characterized by temperature, salinity, total suspended material (TSM), absorption by chromophoric dissolved organic material ( $\left.\mathrm{a}_{\mathrm{CDOM}}\right)$, chlorophyll- $a(\mathrm{Chl}-a)$, eleven accessory pigments, and downwelling diffuse attenuation coefficient, $K_{d}$, for the time of field acquisition; see [35] for the detailed methodology employed for water analysis. All parameters and constituents (summarized in Table 1) were comparable with Sidney Spit or nearby measurements taken at the same time of year, 
although TSS had greater variability [36,37]. The measured concentrations clearly characterize a case 2 water type.

Table 1. Water optical constituents profile for Sidney Spit field sites.

\begin{tabular}{rcc}
\hline & Average & Range \\
\hline Temperature & $11.5^{\circ} \mathrm{C}$ & $11.3-12.2^{\circ} \mathrm{C}$ \\
Salinity & $29 \mathrm{ppt}$ & $28.9-29.4 \mathrm{ppt}$ \\
a & $0.24 \mathrm{~m}^{-1}$ & $0.18-0.33 \mathrm{~m}^{-1}$ \\
$\mathbf{T S M}$ & $4.03 \mathrm{~g} \mathrm{~m}^{-3}$ & $2.25-6.08 \mathrm{~g} \mathrm{~m}^{-3}$ \\
TOC & $47.60 \%$ & $32.7-65.3 \%$ \\
Chl $\boldsymbol{a}$ & $2.44 \mathrm{mg} \mathrm{m}^{-3}$ & $1.28-7.23 \mathrm{mg} \mathrm{m}^{-3}$ \\
\hline
\end{tabular}

The euphotic water column was not stratified. The organic fraction comprised nearly half (average $47.6 \%$ ) of the total suspended matter at the site due to organic detritus produced and entrained by the eelgrass beds. Higher TSM values $\left(5.00-6.00 \mathrm{~g} \mathrm{~m}^{-3}\right)$ were typically found closer to shore, while a (average $=0.24 \mathrm{~m}^{-1}$ ) and Chl- $a$ (average $=2.44 \mathrm{mg} \mathrm{m}^{-3}$ ) did not appear to follow a clear spatial pattern. The most prevalent pigment was chlorophyll- $a$, followed by fucoxanthin, and then chlorophyll-c, a pigment composition characteristic of diatom species [38], which are described as typical of this region [39]. Peridinin and diadino, marker pigments of dinoflagellates, were present in varying amounts, with typically higher concentrations in more open, deep waters and little to none in the shallow lagoon. Some areas of the lagoon however had noteworthy levels of alloxanthin, a marker for Cryptophyceae [40].

The relative magnitude of the diffuse downwelling attenuation coefficients, $K_{d}$ (Figure 2), was related to the distribution of the water constituents. Water's exponential attenuation toward the NIR spectral region resulted in rapid $\mathrm{K}_{\mathrm{d}}$ increase beyond $710 \mathrm{~nm}$, while the characteristic blue absorption by CDOM, blue and red absorption by Chl- $a$ and red scattering by TSM [41] caused higher $\mathrm{K}_{\mathrm{d}}$ values in those ranges. The lowest $\mathrm{K}_{\mathrm{d}}$ values occurred between 500 and $600 \mathrm{~nm}$ where attenuation by pigments and other water constituents was lowest.

Figure 2. Downwelling diffuse attenuation coefficients, $\mathrm{K}_{\mathrm{d}}\left(\mathrm{m}^{-1}\right)$, for Sidney Spit at the time of in situ spectra and image acquisition.

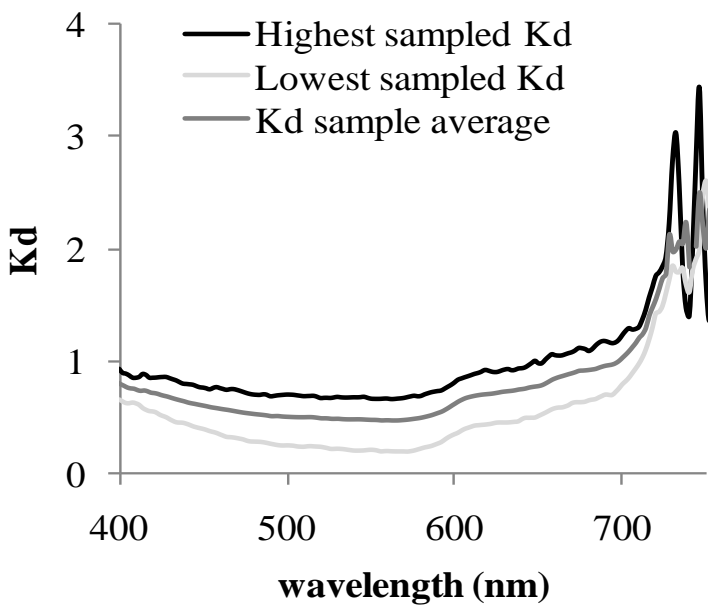




\subsection{Data Acquisition}

Field work was conducted in July/August 2008 and July 2010 to gather information about substrate characteristics and in situ spectral data. Initially, substrate ground-truthing was conducted by photograph, description of substrate type, percent cover (plus shoot density in the case of eelgrass), and GPS marking for a total of 387 sites from June through August 2008, and an additional 120 sites in July 2010. On 14-18 and 31 August 2008, in situ above-water spectra were collected by stratified random sampling within the ground-truthed area from onboard a small motor vessel. The following data were collected at each of these field sites: (1) GPS location; (2) above water photos and underwater videography for substrate identification and density estimation; (3) depth; (4) wind speed to correct radiometric measurements for stray light added by the water surface; and (5) above-water hyperspectral measurements for deriving the spectral variables for characterization and separation of substrates. In situ hyperspectral measurements were acquired and processed as follows.

Above-water in situ radiance spectra $(\mathrm{N}=49)$ were measured (Table 2) over the four major substrates, eelgrass (Z. marina) (25 samples), green algae (U. Fenestrata and Enteromorpha spp.) (8 samples), sand (9 samples), and deep water (>30 m) (7 samples). Spectra were collected over a range of: (a) depth: from 1 to greater than $30 \mathrm{~m}$; (b) eelgrass stand density: from 0 to 624 shoots $/ \mathrm{m}^{2}$; and (c) epiphytic algae density and type: filamentous diatoms and red algae Smithora spp. Above-water spectra were not collected for brown algae, which was found to have minimal presence at the time of acquisition (few small patches, all smaller than $1 \mathrm{~m}^{2}$ ).

Table 2. Benthic substrates present at the Sidney Spit study site and number of spectral samples acquired for each. $E=$ eelgrass, $\mathrm{Ag}=$ green algae, $\mathrm{S}=$ sand, $\mathrm{dW}=$ water $>30 \mathrm{~m}$ deep, $\mathrm{d}=$ deep, $\mathrm{s}=$ shallow.

\begin{tabular}{|c|c|c|c|c|}
\hline $\begin{array}{l}\text { Field } \\
\text { photo } \\
\end{array}$ & $\begin{array}{c}\text { Common } \\
\text { name }\end{array}$ & $\begin{array}{l}\text { Latin } \\
\text { name }\end{array}$ & Abbr. & $\begin{array}{c}\text { Above-water } \\
\text { spectra (n) }\end{array}$ \\
\hline & Eelgrass & $\begin{array}{l}\text { Zostera } \\
\text { marina }\end{array}$ & $\begin{array}{l}\mathbf{s E} \\
\mathrm{dE}\end{array}$ & $\begin{array}{l}21 \text { shallow } \\
4 \text { deep }\end{array}$ \\
\hline & $\begin{array}{l}\text { Green algae: } \\
\text { Sea Lettuce }\end{array}$ & $\begin{array}{c}\text { Ulva } \\
\text { fenestrata }\end{array}$ & sAg & $\begin{array}{l}6 \text { shallow } \\
0 \text { deep }\end{array}$ \\
\hline & $\begin{array}{l}\text { Green algae: } \\
\text { Filamentous }\end{array}$ & $\begin{array}{c}\text { Enteromorpha } \\
\text { spp. }\end{array}$ & sAg & $\begin{array}{c}2 \text { shallow } \\
0 \text { deep }\end{array}$ \\
\hline & Sand & - & $\begin{array}{l}\text { sS } \\
\text { dS }\end{array}$ & $\begin{array}{l}6 \text { shallow } \\
3 \text { deep }\end{array}$ \\
\hline & Deep water (>30 m) & - & $\mathbf{d W}$ & 7 \\
\hline
\end{tabular}

Total water leaving radiance $\left(\mathrm{L}_{\mathrm{T}}(\lambda), 40^{\circ}\right.$ from nadir) and sky radiance $\left(\mathrm{L}_{\text {sky }}(\lambda), 40^{\circ}\right.$ from zenith) were measured one metre above the water surface using a Satlantic HyperSAS mounted on a tripod in 
the boat (Figure 3(a)). The radiance sensors had a half-angle field of view (FOV) of $3^{\circ}$, two-nanometre spectral resolution and a spectral range of 350-800 nm. Total irradiance $\left(E_{S}(\lambda)\right.$, cosine collector at zenith) was measured with a Satlantic OCR-3000 sensor [42,43] mounted on a dowel on the highest position of the boat (Figure 3(b)). These spectral measurements were acquired continuously (one spectra every two seconds) for a period of 40 seconds, for a sample number of $n=20$ spectra per site, while effort was made to maintain a $\mathrm{L}_{\mathrm{T}}$ sensor viewing geometry of $90^{\circ}$ from the sun to avoid specular reflection $[44,45]$. All measurements were made in clear weather with less than 20 percent cloud cover, low wind speeds $\left(<10 \mathrm{~m} \mathrm{~s}^{-1}\right)$, and solar zenith angle between $30^{\circ}$ and $60^{\circ}$ [45-47].

Figure 3. Radiometers used to acquire in situ field spectra above water from the boat. The HyperSAS $L_{\text {sky }}$ and $\mathrm{L}_{\mathrm{T}}$ sensors (a) were mounted on a frame on a tripod viewing over the side of the boat and the $E_{S}$ cosine collector (b) was mounted vertically on a $2 \mathrm{~m}$ dowel at the highest point on the boat.

(a)

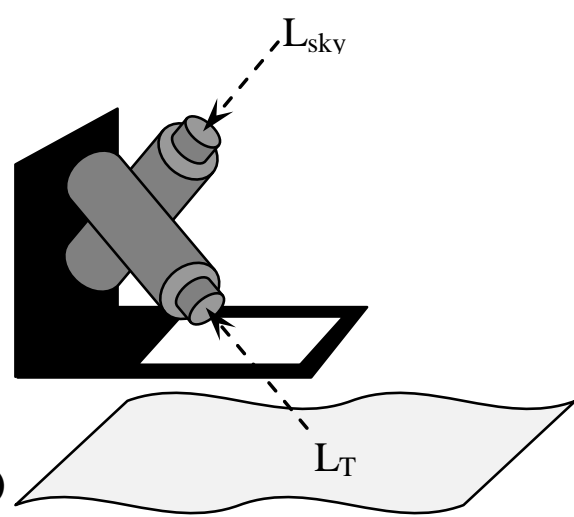

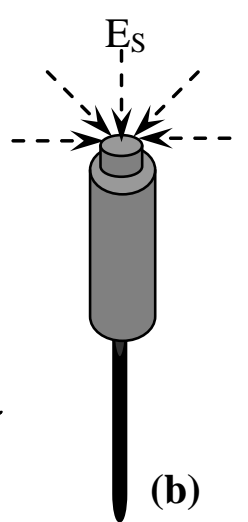

Endmember spectra were also measured. Samples of each substrate were collected and transported in seawater in a cooler. Within thirty minutes of collection, three or more samples of each substrate were laid flat, four layers thick, on black canvas and measured with the HyperSAS radiometer. In the case of eelgrass, blades were measured before and after removing epiphytes with a soft brush. Measurements were made at $31 \mathrm{~cm}$ height with the same sensor-solar geometry configuration as the above-water spectra, and samples were three times the diameter of the field of view to ensure that the canvas did not impact the spectra. Each sample was rearranged and measured three times and then averaged. These measurements represented the "pure" spectra of each cover type without the spectral influence of water optical constituents and adjacent/underlying substrates and served as the basis of evaluation of water column correction of the above water in situ spectra.

To remove possible sun glint outliers from the above-water spectral measurements, $\mathrm{L}_{\mathrm{T}}$ spectra containing values exceeding 1.5 standard deviations from the mean spectrum of the site were removed from the dataset [45]. The remaining radiance measurements were converted to above-water remote sensing reflectance $\left(\mathrm{R}_{\mathrm{rs}}(\lambda)\right)$ according to Equations (1-3) [48] based on modified Fresnel reflectance glint correction algorithm S95, which removed any remaining sky-glint and standardized for variability in solar angle, irradiance, and sea surface state between measurements [44,45]. All remaining remote sensing reflectance spectra from the acquisition interval were then averaged. Note that for the remainder of the text following Equation (1), the wavelength symbol $(\lambda)$ will be omitted from all 
spectral terms for simplicity. However, all spectral quantities are wavelength dependent unless otherwise stated.

$$
\begin{gathered}
R_{r s}^{(0+)}(\lambda)=\left(L_{T}(\lambda)-\rho^{\prime} \cdot L_{s k y}(\lambda)\right) / E_{S}(\lambda) \\
\rho^{\prime}=0.0256+0.00039 \mathrm{~W}+0.000034 \mathrm{~W}^{2}, \text { when } \mathrm{L}_{\text {sky }}(750) / \mathrm{E}_{\mathrm{S}}(750)<0.05 \\
\rho^{\prime}=0.0256, \text { when } \mathrm{L}_{\mathrm{s}}(750) / \mathrm{E}_{\mathrm{S}}(750) \geq 0.05
\end{gathered}
$$

where $\rho^{\prime}$ is the proportionality factor relating the amount of sky radiance reflected off of the sea surface to the total sky radiance, and is dependent on wavelength $(\lambda)$, wind speed (W), and the proportion of cloud cover present in the sky radiance distribution as defined by the ratio $\mathrm{L}_{\mathrm{s}}(750) / \mathrm{E}_{\mathrm{s}}(750)$, which represent sky radiance and irradiance at $750 \mathrm{~nm}$ respectively. When sky conditions are clear $\left(\mathrm{L}_{\text {sky }}(750) / \mathrm{E}_{\mathrm{S}}(750)<0.05\right)$, $\rho^{\prime}$ varies with wind-generated surface roughness, which increases reflections off of the water surfaces. Under cloudy conditions, $\rho^{\prime}$ is independent of wind speed because the diffuse light limits glint $[44,48]$.

A vertical offset error was inherent in each spectra, likely because every spectral acquisition has a slightly different $\rho$ ' value, which can only be estimated through modeling (Equations (1-3)) and cannot be known with absolute certainty. To correct this error, each spectrum was offset by a constant value equal to its mean reflectance value from 750 to $800 \mathrm{~nm}$, which standardized each spectrum to a near-infrared (NIR) value of zero in this range. The validity of this method was verified by simulating a case 1 IOP model in Hydrolight [49,50] with Chl- $a=2.1 \mu \mathrm{g} / \mathrm{L}$ and average ooid sand bottom at $0.5 \mathrm{~m}$ depth. The modeled NIR reflectance values were zero beyond $750 \mathrm{~nm}$. Finally, all in situ spectra were cropped below 400nm to avoid low signal-to-noise data [51] and to match the calibrated range of imagery to which the results of this study will be further applied.

Sun-glint and NIR correction were not necessary for endmember spectra as they were not submerged. The measured radiance spectra were converted to remote sensing reflectance as follows:

$$
R_{r s}=L_{T} / E_{S}
$$

After spectra corrections, six benthic classes were defined based on substrate type and depth: deep water (>30 m), deep sand and deep eelgrass (>3 m); shallow sand, shallow eelgrass and shallow green algae $(<3 \mathrm{~m})$. No green algae sites could be found deeper than three metres and hence representative spectra are absent from this study. The three meter threshold was defined because preliminary analysis of the in situ spectra for each substrate showed noticeable reflectance magnitude differences beyond this depth, particularly in the 700-750 nm spectral region. This threshold is also in agreement with previous in situ measurements and radiative transfer models [52] as well as image analyses [53-55], which found seagrass species and broad cover classes to be inseparable beyond three metres. Depth stratification has been shown to improve classification accuracy by ensuring that dense shallow beds of eelgrass are not confused with sparse deep beds [54,56].

The last step of spectra pre-processing was water attenuation correction. The Maritorena et al. [57] water attenuation correction was applied to the in situ above water remote sensing reflectance, $R_{r s}^{(0+)}(\lambda)$, by first converting it to reflectance just below the water surface, $R_{r s}^{(0-)}(\lambda)[58]$ : 


$$
R_{r s}^{(0-)}=\frac{R_{r s}^{(0+)}}{0.52+\left[1.7 \cdot R_{r s}^{(0+)}\right]}
$$

then following Brando et al. [59], solving for the reflectance of the substrate at depth $0.0 \mathrm{~m}$, i.e., water attenuation corrected substrate spectra, $R_{r s}^{b}$, (Equation (7)) in Maritorena's equation [57] (Equation (6)),

$$
\begin{aligned}
& R_{r s}^{(0-)}=R_{r s}^{d p(0-)}+\left(R_{r s}^{b}-R_{r s}^{d p(0-)}\right) \cdot e^{-2 K_{d} z} \\
& R_{r s}^{b}=\frac{R_{r s}^{(0-)}-R_{r s}^{d p(0-)} \cdot\left(1+e^{-2 K_{d} z}\right)}{e^{-2 K_{d} z}}
\end{aligned}
$$

where $\mathrm{z}$ is the substrate depth measured concurrent with spectral acquisition, $\mathrm{K}_{\mathrm{d}}$ is the diffuse downwelling attenuation coefficient of the water, and $R_{r s}^{d p(0-)}$ is the reflectance of optically deep water (>30 $\mathrm{m}$ depth). The efficacy of the water column correction was assessed by comparing the resulting spectra to measured endmember spectra of the same benthic class.

The depth limit for this correction was assumed to be the same as the average depth at which eelgrass is no longer discernable from deep water (i.e., becomes "optically deep"). Following [19], the detectability threshold of a given submerged substrate occurs when the second term of Maritorena's equation (Equation (6)) equals the detecting threshold of the sensor in reflectance terms $\left(R_{r s}^{D T}\right)$, as expressed below:

$$
\left\lfloor R_{r s}^{b}-R_{r s}^{d p(0-)}\right\rfloor \cdot e^{-2 K_{d} z}=R_{r s}^{D T}
$$

In the case of the in situ spectral data, $R_{r s}^{D T}$ was defined as the wavelength-dependent standard deviation of a homogeneous in situ reflectance measurement of optically deep water. In the case of imagery, it was defined as the wavelength-dependent standard deviation of reflectance within a homogeneous $33 \times 33$ pixel optically deep water region $[59,60]$. The detectability depth limit of each substrate was computed by solving for $\mathrm{z}$ in Equation (6):

$$
z=\frac{1}{2 K_{d}} \cdot \ln \left[\frac{R_{r s}^{b}-R_{r s}^{d p}}{R_{r s}^{D T}-R_{r s}^{d p}}\right]
$$

Beyond this depth, $z$, the substrate is no longer discernable from deep water.

\subsection{Data Reduction and Variable Selection}

Identifying Major Spectral Variables

To identify major spectral variables in the in situ spectra, three methods were employed. First, visual comparison between the mean and 95\% confidence interval (Figure 4) spectra for each class provided a preliminary list of reflectance peaks and valleys that appeared capable of separating eelgrass from other substrates. If a peak or valley location of a specific substrate did not overlap with that of any other substrate, it was considered unique to that substrate. Second, the first derivative curve for each spectral curve was calculated to establish the exact location ( $\left.R^{\prime} \lambda\right)$ where these major features occurred [61]. It has been observed that while the spectral measurements of a single substrate can be variable in reflectance magnitude, spectral shape is typically retained [62]. Therefore, the third step 
incorporated spectral shape by calculating the ratios and slopes (denoted $\lambda: \lambda$ and $s \lambda-\lambda$ respectively) between the absorption and reflectance features identified in first derivative analysis. The results were compiled into a list of 23 indices (Table 3). Fourteen published vegetation indices were calculated and added to the list along with the first derivative values at each wavelength.

Figure 4. (a) Average above-water reflectance with 95\% confidence interval for each benthic substrate type and (b) major reflectance (grey) and absorption (black) features for each benthic substrate with $95 \%$ confidence interval, as derived by first derivative analysis.

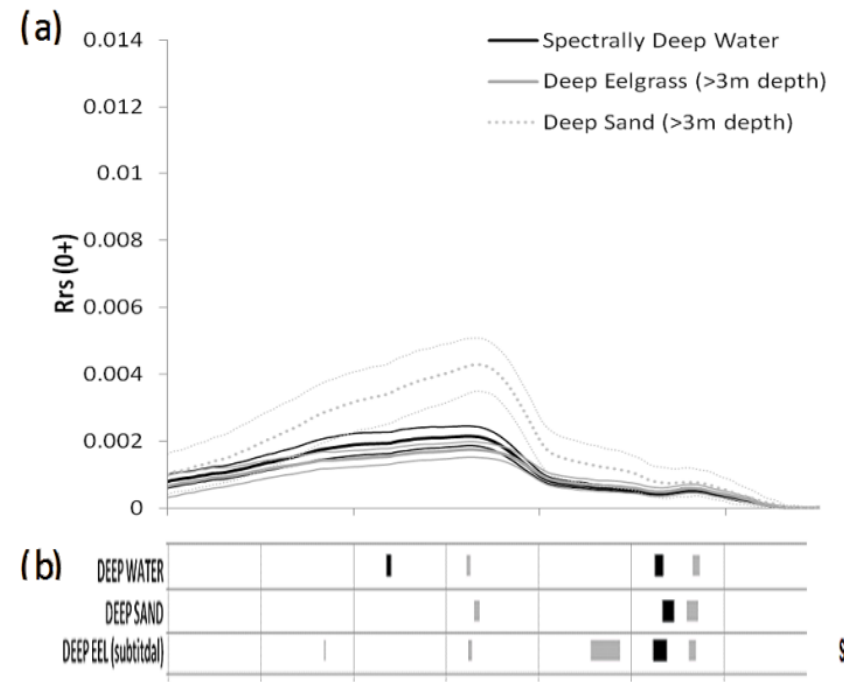

$\begin{array}{llllll}400 & 450 \quad 500 & 550 & 600 & 650 & 700 \\ & \text { Wavelength }(\mathrm{mm}) & \end{array}$

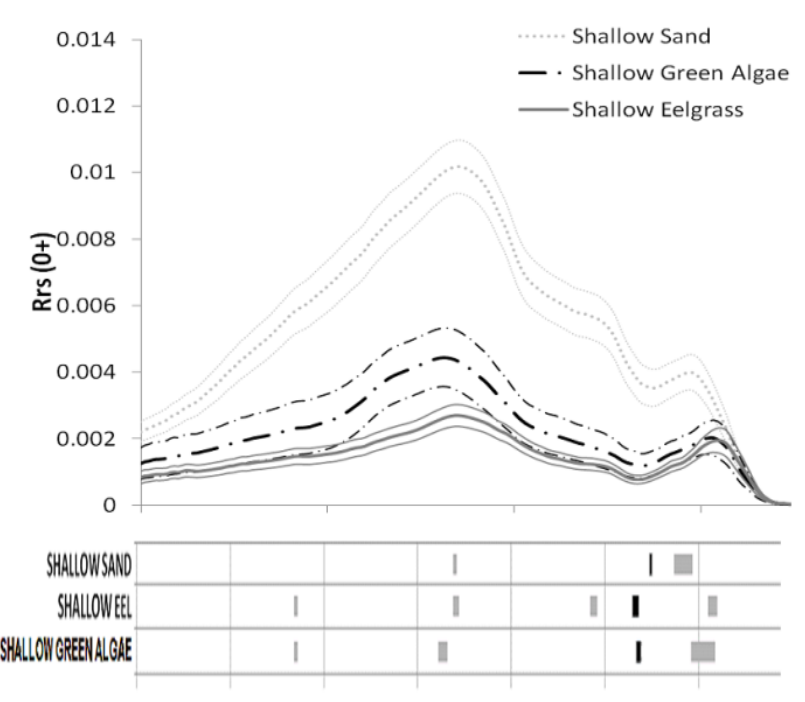

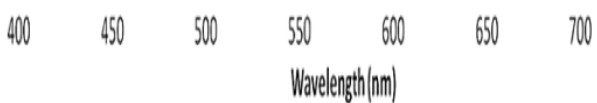

Table 3. List of indices (spectral slopes, denoted s, and ratios, denoted r) defined by visual examination and first derivative analysis.

\begin{tabular}{lcll}
\hline Wavelengths & $\begin{array}{c}\text { Slope(s) } \\
\text { Ratio(r) }\end{array}$ & Description & Reference \\
\hline 480,490 & s,r & Chl blue absorption & This study \\
500,530 & s,r & Green peak: Ascending edge to 530 nm shoulder & This study \\
536,566 & s,r & Greek peak: Ascending edge shoulder to max & This study \\
500,566 & r & Max blue absorption: Max green reflectance & This study \\
566,600 & s,r & Green peak: Descending edge & This study \\
620,640 & s,r & Chl- $b$ \& water red absorption: Descending slope & This study \\
630,640 & s,r & Detect diatom epiphytes & This study \\
650,660 & s,r & Chl red absorption: Descending edge & This study \\
566,670 & r & Chl max green reflectance: Max red absorption & {$[63]$ (672:550) } \\
566,694 & r & Green peak: Sand NIR peak & This study \\
566,710 & r & Green peak: Vegetation NIR peak & [64] \\
570,710 & r & Green peak: Vegetation NIR peak & This study \\
670,700 & s,r & Red edge: Correlated with chlorophyll- $a$ & {$[65]$} \\
668,710 & r & Red edge & {$[66]$ (RVI) } \\
690,710 & r & NIR peak position & {$[64]$} \\
\hline
\end{tabular}


Variable Selection: M-Statistic and Discriminant Analysis

Hyperspectral measurements provide detailed information but also contain high redundancy and yield long data processing times. Furthermore, discriminant analysis, which is applied further in this study, is valid only if the band set contains less than $n-1$ bands (where $n=$ number of training samples) [67]. Since the original spectra, first derivative spectra, and indices totaled over 388 available variables, a dataset reduction was necessary. A two step reduction approach was adopted: M-statistic and discriminant analysis (DA).

The M-statistic is a measure of class separability, which normalizes the difference between the means of two benthic classes $\left(\mu_{1(\lambda)}-\mu_{2(\lambda)}\right)$ by the sum of their standard deviations $\left(\sigma_{1(\lambda)}+\sigma_{2(\lambda)}\right)$ at the specified variable [68]. A large M-statistic indicates good separation between the two classes as within-class variance is minimized and between-class variance maximized. Following Kaufman and Remer [68], $M>1.0$ indicates good class separation and $M<1.0$ indicates poor separation. Since the $\mathrm{M}$-statistic assesses separability for each benthic class pair independently, it offers the beneficial option of focusing only on pairs involving eelgrass. Selecting variables that are important solely to eelgrass classification ensured that in the next reduction step, the discriminant analysis did not compromise eelgrass classification accuracy for the classification accuracy of other substrates.

For the M-statistic analysis, all cases of eelgrass-other substrate class pairing were defined (i.e., eelgrass-sand, eelgrass-green algae, etc.). The M-statistic was then calculated for every variable of each eelgrass-substrate pair case, retaining only those variables with the highest M-statistic values (i.e., the greatest spectral separation between the specified substrate pair). These retained variables were termed "Set 1."

In the second step, a DA with stepwise variable selection was run on the Set 1 variables to eliminate remaining redundancy, yielding "Set 2," the variable set with the minimum number of variables and maximum discriminating ability [67]. A Set 2 was derived for each of the following separability cases: shallow substrates $(<3 \mathrm{~m})$, deep substrates $(>3 \mathrm{~m})$, and both shallow and deep substrates together.

The classification accuracy of each Set 2 was evaluated by applying the DA model equations to a dataset. Rather than separating the dataset into training and testing data, leave one out cross-validation (LOO-CV) was used, whereby each case was classified using a discriminant function derived from all cases except the given case. This maximized the number of samples in both the test (n) and training (n-1) sets while eliminating bias in the classification accuracy value [69]. Prior probabilities of class membership were assigned based on sample sizes to minimize bias due to unequal sample sizes. All models and classification tests were run with 500 bootstrap samples stratified by substrate at a confidence level of $95 \%$.

\subsection{Case Study: Classification of Hyperspectral Airborne Image}

The reduced variable set (Set 2) derived by the previous steps was further tested on hyperspectral imagery. Supervised classification algorithms were applied to an AISA hyperspectral airborne image and validated with ground-truth data in the following scenarios:

Image 1: Full spectral resolution above-water image

Image 1R: Reduced variable above-water image (Set 2 from previous) 
Image 2: Full spectral resolution water-corrected image

Image 2R: Reduced variable water-corrected image (Set 2 from previous)

Hyperspectral high spatial resolution AISA airborne imagery was acquired over Sidney Spit by Terra Remote Sensing on 16 August 2008 at 12:14 during low tide $(0.42 \mathrm{~m})$. The AISA sensor flew at an elevation of $1,500 \mathrm{~m}$, acquiring six flight-lines with a pixel size of $2 \times 2 \mathrm{~m}$ and a swath width of $592 \mathrm{~m}$. The sensor was programmed at 2-nm spectral resolution from $408 \mathrm{~nm}$ to 2,494 nm. Sun glint was minimized by flying in a direction as close as possible to perpendicular with the incident solar angle $[46,70]$.

Prior to classification, the six flight lines were geometrically corrected with Hyperbatch, custom software developed by the Hyperspectral and LiDAR Research Group at the University of Victoria, incorporating the airplane's positional measurements and a LiDAR DEM collected simultaneously with the radiance data. The flight lines were geographically matched to one another manually to minimize residual geo-locational error (average RMSE $=0.60 \mathrm{~m}$ ) and then mosaicked together. A land mask was defined as $\mathrm{DN}(450 \mathrm{~nm})>2,200$. All remaining pixels were land vegetation pixels and were masked out manually with knowledge of the area. To remove scene noise, a Gaussian spectral smoothing window of $10 \mathrm{~nm}$ was applied to each pixel. The image was next atmosphere corrected with empirical line calibration (ELC), using one deep water site and one shallow sand site [71], and corrected for surface glint following Hedley et al. [72]. Subsequently, optically deep water was masked with a threshold of $5.5 \mathrm{~m}$, which was the eelgrass detectability limit of the AISA sensor at $566 \mathrm{~nm}$ following Dekker et al. [19] (Equation (9)). These processing steps resulted in Image 1. Image 1R was created by reducing the Image 1 band range to the variable set (Set 2) selected in Section 2.3: s500-530, R'566, R'580, R'602. Further processing was performed in Image 1 by applying the Maritorena water attenuation correction [57] (Equation (7), where a multibeam bathymetry layer of $1.0 \mathrm{~m}$ interval and $5 \times 5 \mathrm{~m}$ pixel size defined depth, $z$ ), thus resulting in Image 2 . Lastly, Image $2 \mathrm{R}$ was derived by reducing the band range of Image 2 to the selected variable set of 566:600 and 566:710, following the results of water corrected data from Section 2.3.

The minimum distance (MD) supervised classifier was applied to each of the four images. The more statistically complex maximum likelihood (ML) classifier was applied only to the variable reduced images (Images 1R and 2R). ML classification could not be applied to the full spectral resolution images (Images 1 and 2) due to statistical constraints. ML requires the band set to contain less than $n-1$ bands, where $n$ is the number of training samples in each substrate class [31]. In this study, the 175 bands of the full-resolution spectra greatly exceeded n-1, as $n$ varied from 2 to 51 .

Approximately $20 \%$ of the ground-truth data sites $(n=99)$ were used for classifier training. The eelgrass classification accuracy of each image was determined by validation using the remaining $80 \%$ of ground-truth sites $(\mathrm{n}=408)$. Table 4 shows testing and training sample numbers for each substrate class. The classification scheme was as follows: shallow eelgrass (sE), deep eelgrass (dE), shallow sand (sS), deep sand (dS), shallow green algae (sAg), shallow brown algae (sAb), and exposed sea asparagus (eAsp), with the same three meter threshold between shallow and deep classes. Note the addition of two classes, eAsp and sAb, to the classification scheme.

Classification accuracy was evaluated according to eelgrass producer and user accuracies, as well as overall accuracy. Eelgrass producer accuracy represents the percentage of eelgrass testing pixels that 
were classified correctly (i.e., how well the training sites were classified), while user accuracy represents the percentage of pixels designated to the eelgrass class that truly are eelgrass (i.e., how well the classification represents ground-truth) [73]. Overall accuracy considers the accuracy of all substrates; it is the percentage of correctly classified sites of all substrate types combined.

Table 4. Ground truth survey sites for each substrate and number of sites designated as training and validation ROIs for supervised classification.

\begin{tabular}{rccc}
\hline Substrate Classes & $\begin{array}{c}\text { Substrate } \\
\text { Abbr. }\end{array}$ & $\begin{array}{c}\text { Ground-truth } \\
\text { Survey Sites }\end{array}$ & $\begin{array}{c}\text { AISA Training/Validation } \\
\text { Sites ( 20\%/80\%) }\end{array}$ \\
\hline Shallow Eelgrass & $(\mathrm{sE})$ & 265 & $51 / 214$ \\
Deep Eelgrass & $(\mathrm{dE})$ & 19 & $4 / 15$ \\
Green Algae & $(\mathrm{sAg})$ & $129 *$ & $24 / 105$ \\
Shallow Sand & $(\mathrm{sS})$ & 49 & $10 / 39$ \\
Deep Sand & $(\mathrm{dS})$ & 32 & $6 / 26$ \\
Brown Algae & $(\mathrm{sAb})$ & 7 & $2 / 5$ \\
Exposed Sea Asparagus & $(\mathrm{eAsp})$ & 6 & $2 / 4$ \\
\hline
\end{tabular}

* 84 Ulva fenestrata, 23 Enteromorpha spp., and 22 filamentous green algae

\section{Results}

\subsection{Spectral Characteristics of the Benthic Substrates}

Figure 4 summarizes the above-water reflectance curves for the substrates at Sidney Spit. Spectral attenuation features of the water column and constituents were found in all measured spectra and were more pronounced with water depth. For instance, the characteristic water molecule absorption features appeared at $520 \mathrm{~nm}, 570-600 \mathrm{~nm}$ and 700-760 nm [74] and additional absorption features appeared in the blue spectral region due to CDOM, and the blue and red regions due phytoplankton chlorophyll. Reflectance features appeared in the red spectral due to suspended solids-evident in masked red absorption features of benthic vegetation with depth-and at $685 \mathrm{~nm}$ due to chlorophyll fluorescence [75]. The combination of light attenuation by the different water constituents resulted in lower reflectance magnitudes for deep substrates when compared with shallow substrates. Of the shallow substrates, sand showed the highest reflectance, followed by green algae, non-biofouled eelgrass, and biofouled eelgrass in decreasing order. Of the deep substrates, deep sand had higher reflectance, while deep water and deep eelgrass showed lower and very similar magnitudes. The most marked differences between benthic classes occurred in the green spectral range between 500 and $600 \mathrm{~nm}$ (Figure 4), coinciding with the lower $\mathrm{K}_{\mathrm{d}}$ values (Figure 2). Within this spectral region, a broad green peak at the photosynthetic pigment absorption minimum between 560 and $575 \mathrm{~nm}$ was present for all substrates (Figure 4(b)). However the peaks of shallow eelgrass and shallow sand occurred at an average of $5 \mathrm{~nm}$ beyond that of the other benthic types (570 vs. $565 \mathrm{~nm}$ ). Green peak ascending and descending slopes of all classes became steeper with decreasing water depth, and overall, green algae slopes were steeper than those of eelgrass. Eelgrass and green algae exhibited a small shoulder at 470-480 nm, which interrupted the ascending slope. 
The marked absorption feature in the blue range $(400-500 \mathrm{~nm})$ present in all substrates mostly due to CDOM and Chl- $a$, was strengthened in vegetation classes by chlorophyll- $a$ and $-b$, and lutein, and by the additional accessory pigment $\beta$-carotene in green algae. A second major absorption feature appeared in the red region at 662-669 nm for all except sand, which occurred at $675 \mathrm{~nm}$ (Figure 4(b)). This feature is characteristic of chlorophyll- $a$, and $-b$ absorption and was most pronounced in shallow waters because the short water column provided minimal red reflectance from TSM. The presence of epiphytic diatoms on eelgrass and green algae was signified by a unique chlorophyll- $a$ and $-c$ absorption trough between 630 and $640 \mathrm{~nm}$ and a broad spectral flattening caused by fucoxanthin absorption in the 530-566 nm range and physical obstruction of eelgrass green reflectance in the $500-600 \mathrm{~nm}$ range [26,29]. For all shallow vegetation classes, the red-edge occurred in the range of 670-705 $\mathrm{nm}$ and a NIR peak occurred between 687 and $710 \mathrm{~nm}$ (Figure 4).

\subsection{Water Correction}

Generally, the water correction correctly increased reflectance of substrate spectra by one order of magnitude, which is in agreement with endmember spectra. For the substrates shallower than three metres, all corrected spectra averages were within one standard deviation of their respective endmember. Specifically, corrected magnitudes were within $20 \%$ error between 480 and $660 \mathrm{~nm}$ for eelgrass and 500-700 $\mathrm{nm}$ for sand and green algae. The only exception was a 30\% error for green algae from 520 to $620 \mathrm{~nm}$. The blue wavelengths were overcorrected for all shallow benthic substrates. This overcorrection was less for eelgrass when the depth variable was reduced by 0.5 metres in compensation for eelgrass blade height; however, the compensation instead resulted in an underestimation of the long red and short NIR range. All deep eelgrass and deep sand (>3 $\mathrm{m})$ spectra were significantly overcorrected at all wavelengths and held no similarity in spectral shape to their respective endmembers. This suggests that the water column correction is not suitable for substrates deeper than three metres when $\mathrm{K}_{\mathrm{d}}$ is greater than $\mathrm{K}_{\mathrm{d}}(440)=0.82 \mathrm{~m}^{-1}, \mathrm{~K}_{\mathrm{d}}(550)=0.72 \mathrm{~m}^{-1}$, and $\mathrm{K}_{\mathrm{d}}(650)=1.06 \mathrm{~m}^{-1}$, which is the highest $\mathrm{K}_{\mathrm{d}}$ found in a deep water class during this study and used in the sensor depth threshold calculation. Reflectance magnitudes were however within $20 \%$ error between 550 and $590 \mathrm{~nm}$; the portion of the spectrum where $K_{d}$ was lowest (Figure 2) and therefore light penetrated the furthest. This observation is supported by calculations of the HyperSAS depth limit for substrate detection (Equation (9)). The minimum bound of the depth threshold was approximately four metres for sand and three metres for biofouled eelgrass at $600 \mathrm{~nm}$ and dropped to 3 and $2.5 \mathrm{~m}$ respectively by $700 \mathrm{~nm}$ (Figure 5).

\subsection{Spectral Variable Selection}

Indices

Twenty-three indices resulted from the calculation of slopes and ratios between major absorption and reflectance features (Table 3). These indices, together with the original and first derivative wavelengths, totaled 388 variables. 
Figure 5. The depth at which the HyperSAS sensor can no longer distinguish each substrate from optically deep water for the lowest (thin lines) and highest (thick lines) $\mathrm{K}_{\mathrm{d}}$ found at the study site. Calculated as per [19]. Refer to Figure 2 for high and low $K_{d}$ values.

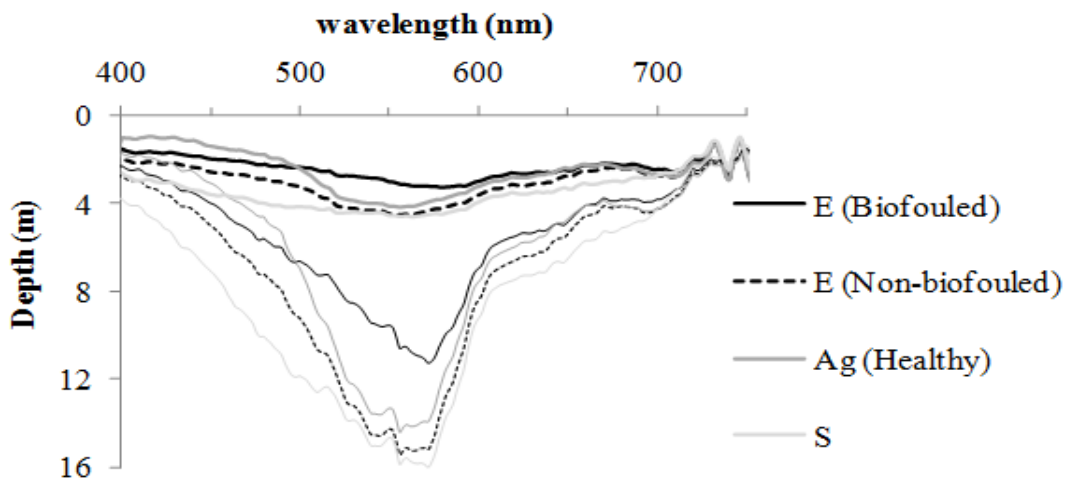

The M-statistic generally defined higher values for the first derivative variables and indices, suggesting that spectral shape was more effective at separating substrates than reflectance magnitude was. The most extreme cases were the substrate pairs sE-sAg and dE-dW, where M-statistic values greater than one were yielded solely by first derivatives and indices. In shallow water $(<3 \mathrm{~m})$, defined Set 1 variables were [R'506, R'532, R'592, s500-530] for sE-sS and [s566-600 and R'524, R'580, $s 500-530, s 566-600,536: 566]$ for sE-sAg. In deep water (>3 m), Set 1 variables were [R'580, 566:600] for dE-dW and [R'474, R'530, R'596, 480-490, 566-600, sR500-R530] for dE-dS.

Set 2 variables for shallow and deep water sub-groups, derived from the discriminate analysis, are reported with total eelgrass classification accuracy in Tables 5 and 6. Shallow water Set 2 variables were s500-530, R'566, R'580, and R'602 for a total classification accuracy of $97 \%$. The only misclassification was of one (out of eight) green algae sample classified as shallow eelgrass. Deep water Set 2 variables were s500-530, R'580, and R'602 for a total classification accuracy of 100\%. Caution should be taken in interpreting this result as the sample size of deep eelgrass was small $(n=4)$, and therefore the $100 \%$ accuracy attained by this set is likely a high estimate. The Set 2 variables for each depth group were pooled to test their combined efficacy in a single classification. The stepwise DA retained all four variables in the model for a total classification accuracy of $98 \%$, misclassifying the same green algae sample as shallow eelgrass. Note that Tables 5 and 6 also include an infrared band index-more specifically the red-edge. Previous studies have suggested a necessity for a benthic classification scheme to include one NIR band to assist in identifying vegetation at the surface of the water (e.g., exposed / floating seagrass and macro algae) [26,76]. The DA had not selected a NIR band, presumably because the dataset included no exposed vegetation samples. To test whether a NIR band would have an impact on the classification of submerged vegetation, the red edge variable 668:710 nm was added to Set 2 and the classification accuracy re-evaluated. The 668:710 variable was found to have no effect on classification, as the eelgrass classification accuracy remained at $98 \%$.

For the water-corrected data set, Set 2 variables were 566:600 and 566:710, with a total classification accuracy of $97 \%$, misclassifying only one green algae sample as eelgrass (Table 7). 
Table 5. Set 2 (DA result) variable set showing spectral separability of shallow eelgrass $(<3 \mathrm{~m})$ from other benthic substrates from above water. A dark box represents good separability (M-statistic > 1) and an empty box denotes poor separability (M-statistic < 1). The value in the box is the M-statistic result.

\begin{tabular}{cc|c|c|cc} 
& \multicolumn{5}{c|}{$\boldsymbol{s E}$ vs.: } \\
\cline { 2 - 6 } Band & SS & SAg & dE & dS & dW \\
\hline \hline s500-530 & 5.73 & 1.63 & 1.90 & 0.49 & 1.76 \\
R'566 & 0.56 & 1.40 & 2.51 & 0.68 & 2.80 \\
R'580 $^{\prime}$ & 2.10 & 1.64 & 0.33 & 3.21 & 1.05 \\
R'602 $^{\prime}$ & 5.70 & 0.64 & 0.56 & 2.46 & 0.25 \\
$\mathbf{6 6 8 : 7 1 0}$ & 2.06 & 0.34 & 1.45 & 1.44 & 1.49
\end{tabular}

Table 6. Set 2 (DA result) variable set showing spectral separability of deep eelgrass (>3 m) from other benthic substrates from above water. A dark box represents good separability (M-statistic $>1)$ and an empty box denotes poor separability (M-statistic $<1)$. The value in the box is the M-statistic result.

\begin{tabular}{ccc|c|cc} 
& \multicolumn{5}{c}{$\boldsymbol{d E}$ vs.: } \\
\cline { 2 - 6 } Band & SS & SAg & SE & dS & dW \\
\hline \hline s500-530 & 11.45 & 2.91 & 1.90 & 4.55 & 0.09 \\
R'566 & 1.62 & 0.56 & 2.51 & 1.47 & 1.10 \\
R'580 & 3.86 & 2.93 & 0.33 & 6.60 & 2.10 \\
R'602 & 8.93 & 1.19 & 0.56 & 4.22 & 0.26 \\
$\mathbf{6 6 8 : 7 1 0}$ & 1.35 & 0.95 & 1.45 & 0.86 & 0.75
\end{tabular}

Table 7. Set 2 (DA result) variable set showing spectral separability of water-corrected shallow eelgrass $(<3 \mathrm{~m})$ from other water-corrected benthic substrates. A dark box represents good separability (M-statistic > 1) and an empty box denotes poor separability $(\mathrm{M}$-statistic < 1). The value in the box is the M-statistic result.

\begin{tabular}{ccc} 
& \multicolumn{2}{c}{$\begin{array}{c}\text { Water-corrected } \\
\text { sE vs.: }\end{array}$} \\
\cline { 2 - 3 } Band & SS & sAg \\
\hline \hline $\mathbf{5 6 6 : 6 0 0}$ & 0.78 & 1.23 \\
$\mathbf{5 6 6 : 7 1 0}$ & 1.76 & 0.77
\end{tabular}

\subsection{Case Study: Classification of a Hyperspectral Airborne Image}

Of the four processing approaches used on the AISA image, the glint and atmospheric corrected (ELC) reduced variable image (1R) showed the best results. MD classification of the full-resolution Image 1 yielded eelgrass producer/user accuracies of 74\%/86\% for shallow $(<3 \mathrm{~m})$ and $72 \% / 90 \%$ for deep ( $>3 \mathrm{~m}$ ) eelgrass; overall accuracy was $63 \%$. Error occurred primarily between sE-sAg and dE-dS. 
Approximately $11 \%$ of all sAg sites were misclassified as $\mathrm{sE}$ (producer error), while $14 \%$ of all pixels classified as $\mathrm{sE}$ were actually $\mathrm{sAg}$ and $29 \%$ of all $\mathrm{dE}$ sites were misclassified as $\mathrm{dS}$ (user error).

Figure 6. Most accurate eelgrass map produced in this study. Image processing steps were: atmospheric correction, glint correction, optically deep water masking, and maximum likelihood (ML) classification of the spectral variables: s500-530, R'566, R'580 and R'602. Eelgrass producer/user accuracies were $85 \% / 96 \%$ for shallow eelgrass and $98 \% / 93 \%$ deep eelgrass. Overall accuracy was $83.2 \%$.

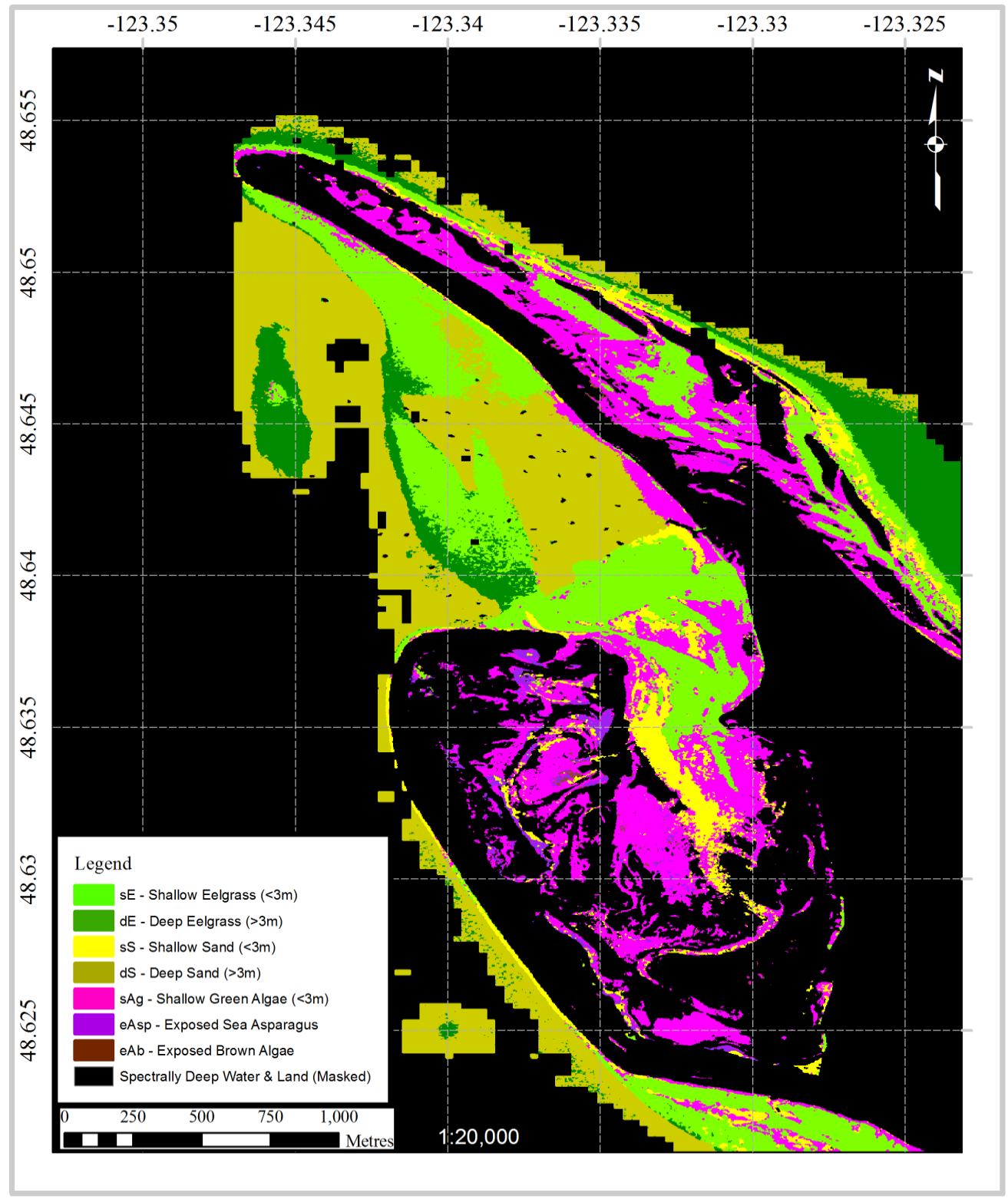

MD classification of the reduced variable Image 1R yielded much lower accuracies: $20 \% / 45 \%$ for shallow $(<3 \mathrm{~m}), 59 \% / 59 \%$ for deep $(>3 \mathrm{~m})$ eelgrass, and $24 \%$ overall accuracy. This was due to considerable confusion between shallow eelgrass ( $\mathrm{sE}$ ) and other green vegetation; $62 \%$ of all $\mathrm{sE}$ training sites were misclassified as eAsp, while $38 \%$ of all pixels classified as sE were actually sAg testing sites. In deep water, there was much confusion between $\mathrm{dE}$ and $\mathrm{dS}$ (40\% user error and 39\% producer error). However, when ML classification was applied to Image $1 \mathrm{R}$, eelgrass producer/user 
accuracy increased considerably to $85 \% / 96 \%$ for shallow $(<3 \mathrm{~m})$ and $98 \% / 93 \%$ for deep ( $>3 \mathrm{~m})$ eelgrass; overall accuracy was $83 \%$. The substrate map produced by this best classification is shown in Figure 6. The major source of confusion was between sE and sAg. Approximately 5\% of all sAg training sites were misclassified as $\mathrm{sE}$ (producer error) while $14 \%$ of all pixels classified as $\mathrm{sE}$ were actually sAg (user error). The sand class resulted in the least confusion at all depths, with $3 \%$ sE-sS producer error and $2 \% \mathrm{dE}-\mathrm{dS}$ producer error. This confusion was mainly near the periphery of the eelgrass bed where sparse density and georeferencing error likely play a role.

The Maritorena water column correction was unsuccessful in the image. At depths over 2.5 metres, the resulting spectral shapes were nonsensical and magnitudes were highly overestimated, especially at wavelengths greater than $600 \mathrm{~nm}$ (b). The water depth in which water-correction error began to occur was consistent with the results of the maximum depth of substrate detection for the AISA sensor (Figure 7(a)), as most substrates had a maximum detection depth of two to three metres in the blue, red, and NIR spectral regions. These spectral regions with shallower detection limit corresponded to the spectral regions in which water constituents, CDOM, TSM, and Chl- $a$ had the greatest attenuating effect, and therefore highest $K_{d}$ values (Figure 7(a)). As a result, Images 2 and $2 \mathrm{R}$ yielded the lowest accuracies. Shallow eelgrass producer/user accuracies of Image 2 were $8 \%$ 196\% and total accuracy was $25 \%$. ML classification of Image $2 \mathrm{R}$ showed some improvement over the MD classification of Image 2. Shallow eelgrass accuracies were $22 \% / 81 \%$ and overall accuracy was $43 \%$.

Figure 7. (a) Depth restriction at which the AISA sensor can no longer distinguish between each substrate and deep water (solid lines) and average Kd value for the scene (dotted line) derived from in situ in water spectral profiles. Depth restriction is wavelength dependent and varies inversely with $\mathrm{K}_{\mathrm{d}}$. (b) Spectra of medium density eelgrass beds with epiphytes at varying depths extracted from the Maritorena water column corrected AISA image.
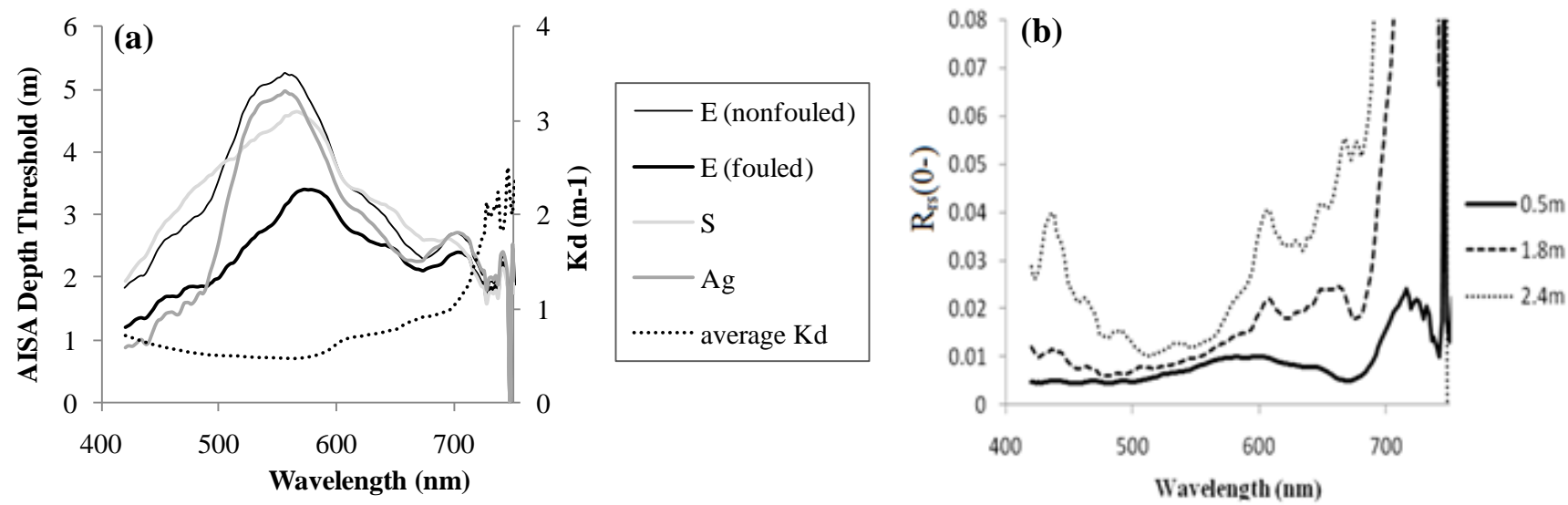

\section{Discussion}

Can Submerged Eelgrass be spectrally Distinguished from other Submerged Substrates? If so, What Spectral Variables (Bands and/or Band Slopes/Ratios) Offer the Most Accurate Separation among Substrates with the Least Redundancy? 
Eelgrass and its associated substrates were spectrally distinct and the spectral shapes and relative magnitudes were in agreement with reported in situ above-water measurements [62,77-79] and pure endmember measurements [19,26,57,80-83]. Statistical variable reduction provided a set of spectral variables offering the greatest separation among two depth classes of eelgrass and four other benthic substrates within above-water and water-corrected data sets. In both datasets, spectral ratios, slopes and first derivatives were more effective at separating benthic substrates than absolute values of reflectance were, suggesting that spectral shape was more important for separating the benthic substrates than magnitude was. This is in agreement with other published results [62,79]. The selected variable set was s500-530, R'566, R'580, and R'602 for above-water data and 566:600 and 566:710 for water-corrected data.

In the visible wavelengths, absolute and relative reflectances of a submerged substrate are the result of both the total and the relative concentrations of substrate pigments, as well as constituents in the overlying water column. Accordingly, the selected slope between 500 and $530 \mathrm{~nm}(s 500-530)$ is likely related to absorption by CDOM, chlorophyll, and lutein (a xanthophyll) in the blue spectra in relation to green reflectance. On one hand, the blue absorbing pigments chlorophyll- $a$, $-b$, and lutein (432 nm, $475 \mathrm{~nm}$, and 440-460 nm, respectively [84]), are present in both green algae and eelgrass. On the other hand, green algae contains the higher lutein concentrations and the additional blue-green (400-505 $\mathrm{nm})$ absorbing accessory pigment $\beta$-carotene [38], thus resulting in a steeper spectral curve between 500 and $530 \mathrm{~nm}$ than that of eelgrass (Figure 4). However, the role of $\beta$-carotene is likely minor compared to the strong spectral influence of epiphytes (diatoms and Smithora) in the 500-530 nm region. In addition to physically blocking eelgrass green reflectance, diatoms have a primary accessory pigment, fucoxanthin, with a major absorption feature at 500-590 $\mathrm{nm}$. This is in agreement with the biofouled/non-biofouled eelgrass and green algae endmember spectra (Figure 8). The 500-530 nm slope was even flatter for eelgrass colonizing shallow waters, possibly due to one or more of the following: a shorter water column and therefore less blue absorption from CDOM and phytoplankton Chl- $a$, the presence of photoprotective anthocyanins that absorb in the range of 500-550 nm [85], or possible greater epiphyte coverage in shallow waters (personal observation). Shallow sand exhibited the steepest s500-530 due to its characteristically high green and red reflectance relative to blue absorption by CDOM and Chl- $a$ in the water column. Additionally, the s500-530 provided poor separation between deep eelgrass and optically deep water (Table 6) because the attenuating effects of the deeper water column obscured the absorption/reflectance features of eelgrass.

Another selected variable, the first derivative value at $566 \mathrm{~nm}$ (R'566), represented the peak of green reflectance and occurred at slightly longer wavelengths in shallow eelgrass and all depths of sand. In eelgrass, this is likely due to the absorptive effects of anthocyanins at the range 500-550 nm displacing the derivative. For sand it was likely due to the high reflectance in the green to red wavelengths characteristic of a mineral signature [57]. The green peak of deep (>3 m) substrates was probably skewed to shorter wavelengths due to strong attenuation by water, which occurs at 570-600 nm [74]. Other selected first derivative values, at $580 \mathrm{~nm}$ and $602 \mathrm{~nm}$, represented, respectively, the descending slope of the green peak and the inflection point of the red absorption feature. These features were both significantly flatter for eelgrass, likely due to epiphyte presence, which increased reflectance between 566 and $640 \mathrm{~nm}$ [26], and photoprotective anthocyanins reflecting 
in the $600-640 \mathrm{~nm}$ region [85]. R'580 provided good separation between eelgrass and every substrate regardless of depth.

Figure 8. Endmember spectra of healthy and senescent green algae and biofouled, non-biofouled and senescent eelgrass. Classifications exhibit confusion between healthy green algae and non-biofouled eelgrass as well as senescent green algae and bio-fouled eelgrass.
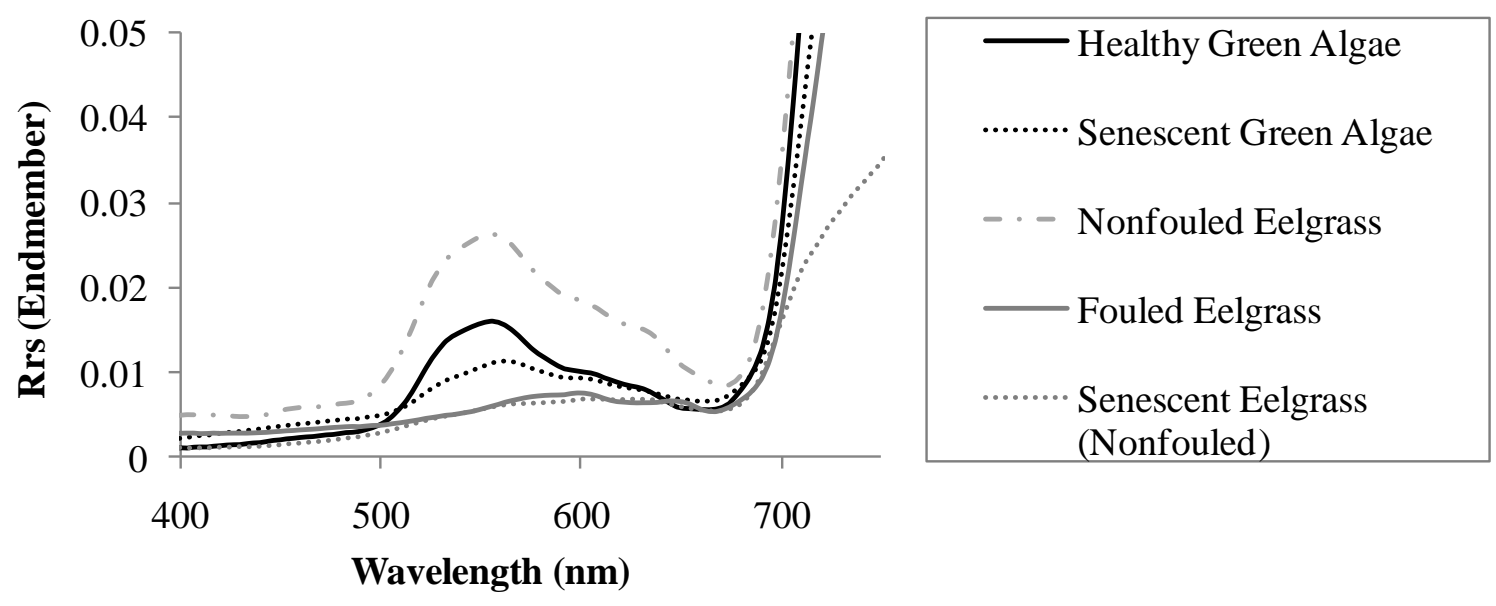

Wavelength (nm)

Lastly, the manually introduced 668:710 ratio identified the vegetation "red edge." Because NIR is attenuated exponentially at the water surface [24], the red edge is characteristic only of shallow vegetation. Therefore a low 668:710 ratio was seen only in shallow ( $<3 \mathrm{~m})$ eelgrass and algae, enabling separation of shallow eelgrass from all other substrates except shallow green algae (Table 5). Although our results showed that this ratio had no effect on the accuracy of the final model, it could have potential for separating submerged vegetation from that which is exposed or floating [26,76].

The variables selected for the water corrected data set were different than those selected for the above-water data set. The variables were 566:600 and 566:710. The green to red ratio 566:600 separated eelgrass from green algae (Table 7). It should be noted that this ratio did not separate non-biofouled eelgrass from green algae $(M-s t a t i s t i c=0.29)$. The ratio was negative for green algae and non-biofouled eelgrass, due to red absorption and green reflectance by $\mathrm{Chl}-a$, and was positive for biofouled eelgrass, due to the characteristic effects of epiphytes: dampening of green reflectance and increase of red reflectance at $590 \mathrm{~nm}$ [26] (Figure 8). The green to NIR ratio, 566:710, separated eelgrass and sand (Table 7) based on presence $v$ s. absence of the red-edge characteristic of vegetation. The ratios selected for water-corrected spectra held similarity to some of the variables selected for the above-water data. The 566:600 ratio represented substrate properties similar to the R'566 and R'580 variables of the above-water variable set, while the 566:710 ratio was similar to the above-water 668:710 ratio. It can then be inferred that the remaining selected above-water variables, s500-530 and R'602, either are more dependent on attenuation features created by water constituents, or add additional spectral information to compensate for that lost through attenuation by water constituents.

The above-water variable set of s500-530, R'566, R'580, and R'602 was selected by both a two-stage classification stratified by depth (less than and greater than $3 \mathrm{~m}$ ) and a single classification addressing all six depth-substrate classes simultaneously. Therefore, assuming adequate atmospheric 
correction, it should be possible to retrieve an eelgrass distribution map for Sidney Spit by applying a classifier which utilizes discriminant functions, e.g., the maximum likelihood (ML) classifier [86], to a remotely sensed image reduced to the selected variables without requiring areal stratification by depth. Additionally, the results show that eelgrass image classification with the selected variables should be robust to atmospheric interference because both (above-water and water corrected) variable sets avoid the blue wavelengths. Accuracy may not, however, be robust for more turbid waters; as turbidity increases, light attenuation in the water increases, causing the maximum depth of eelgrass detection to become shallower.

To calculate these variables in an above-water remotely sensed image, one would require ten bands of $4 \mathrm{~nm}$ bandwidth: R500, R530, R554, R568, R578, R582, R600, R604, R668, R710 nm. A water-corrected image would require three bands of $4 \mathrm{~nm}$ bandwidth: R566, R600, and R710. These bands are in agreement with Fyfe's guidelines for an appropriate seagrass classification band set [26]. The guidelines state that the bands should be narrower than the spectral features they represent and should not overlap with any other spectral feature. They should be centered on or shouldering both sides of major absorption and reflectance features of all substrates present, including seagrass which is both non-fouled (suggesting 500, 550, 620, and $675 \mathrm{~nm}$ ) and fouled (575, 590, and $640 \mathrm{~nm}$ ) and should include one NIR band to discern exposed and floating vegetation. The above-water variables, targeted the peak (R'566) and shoulders (s500-530 \& R'580) of the green reflectance maxima, the red absorption feature (R'602 \& 668:710), the epiphyte reflectance region (R'580), and the vegetation NIR reflectance feature/red edge (668:710). The defined water-corrected variables targeted the green reflectance peak maxima and eelgrass epiphyte reflectance features (566:600) as well as the vegetation NIR reflectance feature/red edge (566:710). However, while Fyfe's recommendations are based on reflectance, this study selected relative measures of reflectance, which capture spectral shape.

How Effective are these Spectral Variables for Detecting Eelgrass in a Hyperspectral Airborne Image?

The results of our case study suggest that hyperspectral airborne imagery, such as the one acquired with AISA, can produce accurate maps of eelgrass. High accuracy (85\%) was achieved when classifying atmospheric and glint corrected, reduced-variable AISA imagery with a ML algorithm. This result emphasizes the importance of variable reduction because the ML classifier could not be applied to the full-resolution hyperspectral data due to restrictions based on the relationship between training sample size and number of input bands [31,67].

The results obtained with a MD classifier were inferior, especially when using the variable reduced band set (20\% overall accuracy). This suggests that the Euclidian distance measurements used in the MD algorithm required a larger set of input bands to improve the classification or that the variable reduction approach eliminated variables containing important information about substrate separability. Further, it is also possible that factors are not accounted for in the in situ spectra that are present in the image - a possibility supported by the lower classification accuracy even of the best image classification compared with in situ accuracy values. These factors include: (1) higher spatial heterogeneity within the $2 \mathrm{~m} \times 2 \mathrm{~m}$ image pixel compared with the HyperSAS field of view; (2) lower substrate certainty due to the combined geolocational errors of the GPS and image georeferencing; and 
(3) greater noise introduced by correcting a $1 \mathrm{~km}$ image atmospheric path, compared with a $1 \mathrm{~m}$ in situ atmospheric path. Such effects would possibly be even larger when up scaling these results to images acquired by satellites such as IKONOS or Quickbird.

Application of the Maritorena water correction [57] to the AISA image produced spectral errors at depths deeper than $2.5 \mathrm{~m}$ (Figure 7(b)). This is because at approximately this depth threshold, submerged substrate and deep water became indistinguishable by the AISA sensor in the blue, red, and NIR spectral regions (Figure 7(a)), where the attenuating effects of water, CDOM, TSM, and Chl- $a$ were the greatest. Classification of the water correct Image 2 revealed that even in shallow areas of less than three metres depth, the results were relatively poor. Since the Maritorena water correction method (Equation (7)) is highly sensitive to errors of depth and $\mathrm{K}_{\mathrm{d}}$ [87], any erroneous estimate of these parameters will result in large errors in estimating the contribution of the water column to the substrate reflectance. This considered, the low classification accuracy of shallow substrates was likely caused by water correction error resulting from the coarse one-meter vertical resolution of the bathymetry layer, or a spatially variable $K_{d}$ throughout the image. The slight improvement of Image $2 R$ (reduced set of bands - in the green and NIR spectra) classification accuracy over Image 2 (full hyperspectral set) emphasizes the role of $K_{d}$ in the water attenuation correction. The improvement is likely owed to the spectral location of the indices in the green portion of the spectrum, where $\mathrm{K}_{\mathrm{d}}$ values were lowest (Figure 2) and water correction of the in situ spectra was most accurate (<20\% error), and in the NIR region, where the water corrected spectra were overestimated but still relatively proportional to their respective substrates. On the contrary, the MD classifier considered all bands of the full resolution water-corrected spectra, including the red and blue spectral regions where large water correction errors were evident. Despite the accuracy improvement, high confusion remained between eelgrass and the other green substrates, sAg and eAsp. Therefore the Maritorena water correction is not recommended for remote eelgrass mapping of submerged substrates where water $K_{d}$ values are similar to those of this study (Table 1). Perhaps more accurate water correction results may be derived by Tassan's model [88], which was developed for turbid coastal waters with horizontal $\mathrm{K}_{\mathrm{d}}$ gradients.

\section{What is the Wavelength-Dependent Depth Limit of Eelgrass Detection in situ and in the Image?}

On average, the maximum depth of substrate detection was 4.5 to $6.0 \mathrm{~m}$ for in situ measurement, and 2.5 (blue, red, and NIR spectral regions) to $5.5 \mathrm{~m}$ (green spectral region) for the AISA image. This is a mid-range value among benthic mapping depth limits found by other authors, which, with Landsat, range from 1.0 to $3.0 \mathrm{~m}$ in modeled CDOM-rich waters $\left(\mathrm{a}_{\mathrm{CDOM}}(400)=15.0 \mathrm{~m}^{-1}\right.$, Chl- $a=6.0 \mu \mathrm{g} \mathrm{L}^{-1}$, $\mathrm{TSM}=6.0 \mathrm{mg} \mathrm{L}^{-1}$ ) [62], approximately $2.0 \mathrm{~m}$ in TSM rich waters $\left(\mathrm{TSM}=15.0 \mathrm{mg} \mathrm{L}^{-1}\right)$ [19] and temperate case 2 waters [21], $3.0 \mathrm{~m}$ in turbid waters with Landsat [52], and $6.0 \mathrm{~m}$ in moderate case 1 waters with IKONOS [89], to $11.0 \mathrm{~m}$ in modeled medium Case 1 waters $\left(\mathrm{a}_{\mathrm{CDOM}}(400)=1.5 \mathrm{~m}^{-1}\right.$, Chl- $a=2.0 \mu \mathrm{g} \mathrm{L}^{-1}, \mathrm{TSM}=2.0 \mathrm{mg} \mathrm{L}^{-1}$ ) [62] and $18.0 \mathrm{~m}$ in very clear tropical case 1 waters with IKONOS, SPOT and CASI [90]. Note that our results with the AISA sensor showed a shallower depth limit, likely due to higher sensor noise and atmospheric influence, as has been suggested by others [19]). A satellite sensor would likely have an even shallower depth constraint, given similar $\mathrm{K}_{\mathrm{d}}$ conditions. 
The maximum depth of substrate detection will vary depending on the transparency of the water and the magnitude of substrate reflectance. Using the in situ calculations as an example, if measurements are taken when the water column is relatively clear (for instance, $K_{d(566 \mathrm{~nm})}=0.20 \mathrm{~m}^{-1}$ ), eelgrass may be detected up to a depth of $15.0 \mathrm{~m}$ if not biofouled and $11.0 \mathrm{~m}$ if biofouled. If water is more turbid (e.g., $\mathrm{K}_{\mathrm{d}(566 \mathrm{~nm})}=0.47 \mathrm{~m}^{-1}$ ), the detection may be limited to shallow intertidal areas of $3 \mathrm{~m}$ depth or less (Figure 5).

\section{Conclusions}

The spectral separability of eelgrass from other submerged substrates was demonstrated in this study based on reflectance values from in situ hyperspectral measurements by identifying the spectral variables (bands, slopes, and ratios) for which between-class variability was maximized. The results of this study suggested specific combinations of spectral variables that could be used to map eelgrass distribution with remote imagery, a non-destructive approach that permits repeated measurements in a specific location. The defined variables were further tested in classification of a hyperspectral airborne AISA image.

Based on the in situ data, 95\% accuracy could be achieved when spectrally classifying eelgrass from above water, by applying a discriminant analysis classification procedure with the following set of five indices as inputs: s500-530, R'566, R'580, and R'602 and 668:710. According to these in situ results, if these variables were used to classify a remotely sensed image, it would not be necessary to stratify by depth or mask out optically deep water. The classification should be resilient to slight atmospheric correction errors, as the spectral variable set is independent of the blue wavelengths, where atmospheric interference is the greatest. Effort should be made to collect imagery during times of the year when water is clearest (i.e., attenuation coefficients are low) so that the depth limit of eelgrass detection is maximized.

It should be noted that although discriminant analysis is robust to departures from multivariate normality, and in the case of this dataset, the departures were fairly small, it still remains that the results should be interpreted with more care [91]. Therefore the discriminant analysis is used in this case for exploratory analysis rather than statistical testing. Additionally, stepwise variable selection does not allow variables back into the model once they have been removed; as such, the stepwise method may have limited the variable selection. A neural network technique such as Tabu search [92], which considers more variable combinations, may arrive at a different variable selection.

The reduced variable set did not offer an advantage over the full-resolution dataset when classifying a hyperspectral airborne AISA image with a MD classifier. In fact, the eelgrass classification accuracy of the reduced variable image was markedly lower in this scenario - a result of high confusion between very shallow eelgrass and exposed vegetation. However, the major advantage of the reduced set was in attainment of a suitably small band set to enable use of the more statistically rigorous ML classifier. With ML classification of the reduced variable set, the higher eelgrass accuracies were achieved: over $85 \%$ eelgrass producer and user accuracies and $83 \%$ overall classification accuracy.

Still, supervised classifications, such as the ones used in this study, require a significant amount of ground-truth work. The field portion of a remote mapping project may constitute up to $70 \%$ of project duration, and, if set-up costs (i.e., software) are omitted, may account for approximately $86 \%$ of the 
total project cost if using satellite imagery or $25 \%$ if using airborne imagery (estimates are for SPOT XS and airborne MSS respectively) [93]. Automation is the solution to this issue, and the ultimate goal of remote sensing procedures. Toward the goal of automation, the above-water and endmember spectra measured in this study will be compiled, along with future measurements, into a benthic substrate spectral library. This spectral library will be useful in the future evaluation of automated classification approaches, such as linear spectral unmixing (LSU), or the spectral angle mapper (SAM). An ideal spectral library for this purpose would include a wide array of substrates compiled from a variety of sites (e.g., additional macroalgae and varying sediment types from silt to cobble) and could be continually improved by collaboration with other in situ hyperspectral studies.

The key wavelengths identified in this study are recommended for application with analysis of airborne and satellite imagery when the goal is delineating the spatial distribution of eelgrass. Applying these key wavelengths in the programming of airborne sensors, or the development of coastal based satellite spectral sensors, could yield effective mapping of eelgrass Zostera marina and associated benthic cover in the shallow coastal waters of Sidney Island, B.C., and possibly in other temperate coastal areas. These maps could be used as baseline inventory data and, when merged with other ancillary data layers (e.g., estuarine water flow and sediment loads, salinity, temperature, fish and invertebrate distributions), be used to report on the structure and functioning of coastal ecosystems [94,95]. However, it should be noted that species discrimination in the remote sensing of vegetation is achievable as long as the species and substrates under study are spectrally distinct over space and time [26]. For example, high classification accuracies at Sidney Island are owed in part to the large spectral magnitude differences between eelgrass and sand. Classification of an area where substrates are spectrally darker and more closely resemble the reflectance of submerged eelgrass (e.g., clays with high organic content) may not perform as well [21]. Likewise, plant phenology and water properties vary over time and between locations. Therefore it is recommended that the selected variables and image processing approach be tested on data gathered at Sidney Island over different seasons and at additional areas in the Gulf Islands National Park to confirm whether our suggestions are local- and time-specific, or more widely applicable.

Eelgrass blade orientation must be considered when delineating eelgrass location. At an average length of $1.0 \mathrm{~m}$, strong tidal current can alter the apparent periphery of the bed by about $1.0 \mathrm{~m}$ relative to slack tide when the blades are vertical. However, horizontal blades may provide higher classification accuracy; vertical orientation at slack tide would likely expose more underlying substrate to the sensor, creating a more heterogeneous signal and increasing the chance of substrate misclassification. This assumption was drawn from the results of the present study, where eelgrass producer error occurred largely in areas of spectral mixing in sparse eelgrass or bed peripheries. Further research into the spectral effect of blade orientation is recommended. In the meantime, it is important to be aware of prevailing current regimes of the study site, and whether one chooses to acquire at slack or flowing current, the state of the current should remain consistent throughout all images which are being compared over time. The blade orientation becomes still more important when developing and applying models for eelgrass biophysical parameters such as density and LAI. In this case, care should be taken to acquire imagery at a similar tidal state to that during which the biophysical model was developed. 
Lastly, the area that can be effectively mapped depends on the depth of detection threshold of the sensor. Since the depth threshold varies with water depth and attenuation coefficient, it is recommended that imagery be acquired during the lowest possible tide. In any case, all effort should be made to acquire imagery in the months when waters are clearest, i.e., lowest $\mathrm{K}_{\mathrm{d}}$. Subtidal areas near the depth of detection threshold will still, however, show a higher level of classification error than shallow areas [59], and this error will vary with spatial and temporal variability of $\mathrm{K}_{\mathrm{d}}$. Since reliable temporal monitoring techniques must be functional over a range of conditions [96], it might be necessary to increase the reliability of subtidal eelgrass mapping with additional techniques. For example, Roelfsema stratified image data by depth and turbidity (>3 $\mathrm{m}$ and turbid $v s$. $<3 \mathrm{~m}$ and exposed) [96]. On the shallow/exposed fraction, image classification techniques similar to the present study were applied. The deep and turbid areas, however, were manually digitized based on local knowledge, ground-truthing, IKONOS fused higher resolution panchromatic data, etc. Pe'eri et al. similarly applied manual expert guidance post-classification to separate green macro-algae from eelgrass [97]. The methods of Roelfsema [96] and Pe'eri et al. [97] could be applied as a secondary step to the recommendations of our study.

\section{Acknowledgements}

The authors would like to acknowledge staff at Parks Canada for logistics and technical support, student volunteers for help with collection of field data, Terra Remote Sensing for image acquisition, and the Hyperspectral and LiDAR Research Group at the University of Victoria of Olaf Niemann for radiometric and Hyperbatch geometric correction of imagery. Authors would also like to acknowledge funding sources provided by NSERC and CFI/BCKDF.

\section{References and Notes}

1. Hemming, M.A.; Duarte, C.M. Seagrass Ecology; Cambridge University Press: Cambridge, UK, 2000.

2. Jackson, J.B.C.; Kirby, M.X.; Berger, W.H.; Bjorndal, K.A.; Botsford, L.W.; Bourque, B.J.; Bradbury, R.H.; Cooke, R.; Erlandson, J.; Estes, J.A.; Hughes, T.P.; Kidwell, S.; Lange, C.B.; Lenihan, H.S.; Pandolfi, J.M.; Peterson, C.H.; Steneck, R.S.; Tegner, M.J.; Warner, R.R. Historical overfishing and the recent collapse of coastal ecosystems. Science 2001, 293, 629-638.

3. Fonseca, M.; Cahalan, J. A preliminary evaluation of wave attenuation by four species of seagrass. Estuar. Coast. Shelf Sci. 1992, 35, 565-576.

4. Apostolaki, E.T.; Marba, N.; Holmer, M.; Karakassis, I. Fish farming enhances biomass and nutrient loss in Posidonia oceanica (L.). Estuar. Coast. Shelf Sci. 2009, 81, 390-400.

5. Duarte, C.M.; Chiscano, C.M. Seagrass biomass and production: A reassessment. Aquat. Bot. 1999, 65, 159-174.

6. Sewell, A.T.; Norris, J.G.; Wyllie-Echeverria, S.; Skalski, J.R. Eelgrass monitoring in Puget Sound: Overview of the Submerged Vegetation Monitoring Program. In Puget Sound Research 2001; Puget Sound Water Quality Action Team: Olympia, WA, USA, 2001; 98504-0900. 
7. Borg, J.A.; Rowden, A.A.; Attrill, M.J.; Schembri, P.J.; Jones, M.B. Wanted dead or alive: High diversity of macroinvertebrates associated with living and "dead" Posidonia oceanica matte. Mar. Biol. 2006, 149, 667-677.

8. Thistle, M.E.; Schneider, D.C.; Gregory, R.S.; Wells, N.J. Fractal measures of habitat structure: Maximum densities of juvenile cod occur at intermediate eelgrass complexity. Mar. Ecol. Progr. Ser. 2010, 405, 39-56.

9. Adams, S.M. Feeding ecology of reef fish communities. Trans. Am. Fish. Soc. 1976, 105, 514-519.

10. Duarte, C.M. The future of seagrass meadows. Environ. Conser. 2002, 29, 192-206.

11. Burkholder, J.; Tomasko, D.; Touchette, B. Seagrasses and eutrophication. J. Exp. Mar. Biol. Ecol. 2007, 350, 46-72.

12. Walker, D.I.; Lukatelich, R.J.; Bastyan, G.; McComb, A.J. Effect of boat moorings on seagrass beds near Perth, Western Australia. Aquat. Bot. 1989, 36, 69-77.

13. Marba, N.; Santiago, R.; Diazalmela, E.; Alvarez, E.; Duarte, C. Seagrass (Posidonia oceanica) vertical growth as an early indicator of fish farm-derived stress. Estuar. Coast. Shelf Sci. 2006, 67, 475-483.

14. Diaz-Almela, E.; Marba, N.; Alvarez, E.; Santiago, R.; Holmer, M.; Grau, A.; Danovaro, R.; Argyrou, M.; Karakassis, I.; Duarte, C.M. Benthic input rates predict seagrass (Posidonia oceanica) fish farm-induced decline. Mar. Pollut. Bull. 2008, 56, 1332-1342.

15. Short, F.T.; Wyllie-Echeverria, S. Natural and human-induced disturbance of seagrasses. Environ. Conser. 1996, 23, 17-27.

16. Moore, K.; Wetzel, R. Seasonal variations in eelgrass (Zostera marina L.) responses to nutrient enrichment and reduced light availability in experimental ecosystems. J. Exp. Mar. Biol. Ecol. 2000, 244, 1-28.

17. Zimmerman, R.C. A biooptical model of irradiance distribution and photosynthesis in seagrass canopies. Limnol. Oceanogr. 2003, 48, 568-585.

18. Najjar, R.G.; Pyke, C.R.; Adams, M.B.; Breitburg, D.; Hershner, C.; Kemp, M. Potential climate-change impacts on the Chesapeake Bay. Estuar. Coast. Shelf Sci. 2010, 86, 1-20.

19. Dekker, A.G.; Brando, V.E.; Anstee, J.M. Retrospective seagrass change detection in a shallow coastal tidal Australian lake. Remote Sens. Environ. 2005, 97, 415-433.

20. Ferwerda, J.G.; Leeuw, J.D.; Atzberger, C.; Vekerdy, Z. Satellite-based monitoring of tropical seagrass vegetation: Current techniques and future developments. Hydrobiologia 2007, 591, 59-71.

21. Ackleson, S.G.; Klemas, V. Remote sensing of submerged aquatic vegetation in lower Chesapeake Bay: A comparison of Landsat MSS to TM imagery. Remote Sens. Environ. 1987, 22, 235-248.

22. Hedley, J.D.; Mumby, P.J. A remote sensing method for resolving depth and subpixel composition of aquatic benthos. Limnol. Oceanogr. 2003, 48, 480-488.

23. Kirk, J.T.O. Light \& Photosynthesis in Aquatic Ecosystems; Cambridge University Press: Cambridge, UK, 1994.

24. Mobley, C.D. Light and Water: Radiative Transfer in Natural Waters; Academic Press: San Diego, CA, USA, 1994. 
25. Drake, L.A.; Dobbs, F.C.; Zimmerman, R.C. Effects of epiphyte load on optical properties and photosynthetic potential of the seagrasses Thalassia testudinum Banks ex Konig and Zostera marina L. Limnol. Oceanogr. 2003, 48, 456-463.

26. Fyfe, S.K. Spatial and temporal variation in spectral reflectance: Are seagrass species spectrally distinct? Limnol. Oceanogr. 2003, 48, 464-479.

27. Mazzella, L.; Alberte, R.S. Light adaptation and the role of autotrophic epiphytes in primary production of the temperate seagrass, Zostera marina L. J. Exp. Mar. Biol. Ecol. 1986, 100, 165-180.

28. Werdell, P.J.; Roesler, C.S. Remote assessment of benthic substrate composition in shallow waters using multispectral reflectance. Limnol. Oceanogr. 2003, 48, 557-567.

29. Meleder, V.; Barille, L.; Launeau, P.; Carrere, V.; Rince, Y. Spectrometric constraint in analysis of benthic diatom biomass using monospecific cultures. Remote Sens. Environ. 2003, 88, 386-400.

30. Murphy, R.J.; Tolhurst, T.J.; Chapman, M.G.; Underwood, A.J. Estimation of surface chlorophyll- $a$ on an immersed mudflat using field spectrometry: Accuracy of ratios and derivative-based approaches. Int. J. Remote Sens. 2005, 26, 1835-1859.

31. Richards, J.; Jia, X. Feature reduction. In Remote Sensing Digital Image Analysis: An Introduction, 4th ed.; Chapter 10; Springer: Berlin/Heidelberg, Germany, 2006.

32. Parks Canada. Sidney Spit (Sidney Island). Gulf Islands National Park Reserve of Canada, 2010. Available online: http://www.pc.gc.ca/pn-np/bc/gulf/carte-map-nfl.aspx\#a28 (accessed on 4 January 2011).

33. Robinson, C.; Martel, G. The Status of Eelgrass Meadow (Zostera marina) Health during August 2004-2006 in the New Gulf Islands National Park Reserve of Canada; WSNC Technical Report for Western and Northern Canada Service Centre-Parks Canada; Western and Northern Canada Service Centre-Parks Canada: Winnipeg, MB, Canada, 2007; p. 59.

34. Leatherbarrow, K.E. Monitoring Environmental Impacts of Recreational Boat Anchoring on Eelgrass (Zostera marina L.) and Benthic Invertebrates in the Gulf Islands National Park Reserve of Canada. M.Sc. Thesis, University of Victoria, Victoria, BC, Canada, 2006.

35. O’Neill, J.D. Mapping of Eelgrass (Zostera marina) at Sidney Spit, Gulf Islands National Park Reserve of Canada, Using High Spatial Resolution Remote Imagery. M.Sc. Thesis, University of Victoria, Victoria, BC, Canada, 2010.

36. Robinson, C.L.K.; Yakimishyn, J. Monitoring for the Ecological Integrity of Eelgrass Beds (Zostera marina) in Canada's Coastal National Parks of British Columbia; ParksCanada Resource Conservation Technical Report (Internal Document); Parks Canada: Winnipeg, MB, Canada, 2005; pp. 1-89.

37. Komick, N.M.; Costa, M.P.F.; Gower, J. Bio-optical algorithm evaluation for MODIS for western Canada coastal waters: An exploratory approach using in situ reflectance. Remote Sens. Environ. 2009, 113, 794-804.

38. Rowan, K.S. Photosynthetic Pigments of Algae; Cambridge University Press: New York, NY, USA, 1989.

39. Harrison, P.J.; Fulton, J.D.; Taylor, F.J.R.; Parsons, T.R. Review of the biological oceanography of the Strait of Georgia: Pelagic environment. Canad. J. Fish. Aquat. Sci. 1983, 40, 1064-1094. 
40. Antajan, E.; Gasparini, S. Assessment of Cryptophyceae ingestion by copepods using alloxanthin pigment: A caution. Mar. Ecol. Progr. Ser. 2004, 274, 191-198.

41. Liedtk, J.; Roberts, A.; Luternauer, J. Practical remote sensing of suspended sediment concentration. Photogramm. Eng. Remote Sensing 1995, 61, 167-175.

42. Satlantic Inc. Operation Manual for the HyperSAS; Satlantic Document \#SAT-DN-00212, Revision A; Satlantic Inc.: Halifax, NS, Canada, 2003.

43. Satlantic Inc. Operation Manual for the OCR-3000 (MiniSpec); Satlantic Document \#SAT-DN0069, Revision D; Satlantic Inc.: Halifax, NS, Canada, 2003.

44. Mobley, C.D. Estimation of the remote-sensing reflectance from above-surface measurements. Appl. Opt. 1999, 38, 7441-7455.

45. Hooker, S.B.; Zibordi, G.; Brown, J.W. Above-water radiometry in shallow coastal waters. Appl. Opt. 2004, 43, 4254-4268.

46. Gordon, H.R. Normalized water-leaving radiance: Revisiting the influence of surface roughness. Appl. Opt. 2005, 44, 241-248.

47. Wang, M.H. Effects of ocean surface reflectance variation with solar elevation on normalized water-leaving radiance. Appl. Opt. 2006, 45, 4122-4128.

48. Ruddick, K.G.; Cauwer, V.D.; Park, Y.-J.; Moore, G. Seaborne measurements of near infrared water-leaving reflectance: The similarity spectrum for turbid waters. Limnol. Oceanogr. 2006, 51, 1167-1179.

49. Mobley, C.D.; Sundman, L.K. HYDROLIGHT 4.1 Users' Guide; Sequoia Scientific, Inc.: London, WA, USA, 2000; p. 85.

50. Mobley, C.D.; Sundman, L.K. HYDROLIGHT 4.1 Technical Documentation; Sequoia Scientific, Inc.: London, WA, USA, 2000; p. 76.

51. Cho, H.J.; Kirui, P.; Natarajan, H. Test of multi-spectral vegetation index for floating and canopy-forming submerged vegetation. Int. J. Environ. Res. Public Health 2008, 5, 477-483.

52. Roelfsema, C.; Phinn, S.; Dennison, W.; Dekker, A.; Brando, V. Monitoring toxic cyanobacteria Lyngbya majuscula (Gomont) in Moreton Bay, Australia by integrating satellite image data and field mapping. Harmful Algae 2006, 5, 45-56.

53. Brando, V.E.; Dekker, A.G. Satellite hyperspectral remote sensing for estimating estuarine and coastal water quality. IEEE Trans. Geosci. Remote Sens. 2003, 41, 1378-1387.

54. Phinn, S.; Dekker, A.; Brando, V.; Roelfsema, C. Mapping water quality and substrate cover in optically complex coastal and reef waters: An integrated approach. Mar. Pollut. Bull. 2005, 51, 459-469.

55. Phinn, S.; Roelfsema, C.; Dekker, A.; Brando, V.; Anstee, J. Remote Sensing of Environment Mapping seagrass species, cover and biomass in shallow waters: An assessment of satellite multi-spectral and airborne hyper-spectral imaging systems in Moreton Bay (Australia). Remote Sens. Environ. 2008, 112, 3413-3425.

56. Pasqualini, V.; Pergentmartini, C.; Pergent, G.; Agreil, M.; Skoufas, G.; Sourbes, L. Use of SPOT 5 for mapping seagrasses: An application to Posidonia oceanica. Remote Sens. Environ. 2005, 94, $39-45$. 
57. Maritorena, S.; Morel, A.; Gentili, B. Diffuse reflectance of oceanic shallow waters: Influence of water depth and bottom albedo. Limnol. Oceanogr. 1994, 39, 1689-1703.

58. Lee, Z.; Carder, K.L.; Arnone, R.A. Deriving inherent optical properties from water color: A multiband quasi-analytical algorithm for optically deep waters. Appl. Opt. 2002, 41, 5755-5772.

59. Brando, V.E.; Anstee, J.M.; Wettle, M.; Dekker, A.G. A physics-based retrieval and quality assessment of bathymetry from suboptimal hyperspectral data. Remote Sens. Environ. 2009, 113, 755-770.

60. Wettle, M.; Brando, V.E.; Dekker, A.G. A methodology for retrieval of environmental noise equivalent spectra applied to four Hyperion scenes of the same tropical coral reef. Remote Sens. Environ. 2004, 93, 188-197.

61. Becker, B.L.; Lusch, D.P.; Qi, J. Identifying optimal spectral bands from in situ measurements of Great Lakes coastal wetlands using second-derivative analysis. Remote Sens. Environ. 2005, 97, 238-248.

62. Vahtmae, E.; Kutser, T.; Martin, G.; Kotta, J. Feasibility of hyperspectral remote sensing for mapping benthic macroalgal cover in turbid coastal waters-A Baltic Sea case study. Remote Sens. Environ. 2006, 101, 342-351.

63. Viollier, M.; Belsher, T.; Loubersac, L. Signatures Spectrales des Objets du Littoral. In Proceedings of the 3rd International Colloquium Spectral Signatures of Objects in Remote Sensing, Les Arcs, France, 16-20 December 1985; pp. 253-256.

64. Lichtenthaler, H.K.; Gitelson, A.; Lang, M. Non-destructive determination of chlorophyll content of leaves of a green and an aurea mutant of tobacco by reflectance measurements. J. Plant Physiol. 1996, 148, 483-193.

65. Gitelson, A.; Garbuzov, G.; Szilagyi, F.; Mittenzwey, K.H.; Karnieli, A.; Kaiser, A. Quantitative remote sensing methods for real-time monitoring of inland waters quality. Int. J. Remote Sens. 1993, 14, 1269-1295.

66. Jordan, C.F. Determination of leaf area index from quality of light on the forest floor. Ecology 1969, 50, 663-666.

67. Bandos, T.V.; Bruzzone, L.; Camps-Valls, G. Classification of hyperspectral images with regularized linear discriminant analysis. IEEE Trans. Geosci. Remote Sens. 2009, 47, 862-873.

68. Kaufman, Y.J.; Remer, L. Detetion of forests using mid-IR reflectance: An application for aerosol studies. IEEE Trans. Geosci. Remote Sens. 1994, 32, 672-683.

69. Efron, B. Nonparametric estimates of standard error: The jackknife, the bootstrap and other methods. Biometrika 1981, 68, 589-599.

70. Kay, S.; Hedley, J.D.; Lavender, S. Sun glint correction of high and low spatial resolution images of aquatic scenes: A review of methods for visible and near-infrared wavelengths. Remote Sens. 2009, 1, 697-730.

71. Teillet, P.M.; Slater, P.N.; Ding, Y.; Santer, R.P.; Jackson, R.D.; Moran, M.S. Three methods for the absolute calibration of the NOAA AVHRR sensors in-flight. Remote Sens. Environ. 1990, 31, 105-120.

72. Hedley, J.; Harborne, A.; Mumby, P. Simple and robust removal of sun glint for mapping shallow-water benthos. Int. J. Remote Sens. 2005, 26, 2107-2112. 
73. Story, M.; Congalton, R.G. Accuracy assessment: A user's perspective. Photogramm. Eng. Remote Sensing 1986, 52, 397-399.

74. Morel, A.; Gentili, B.; Claustre, H.; Babin, M.; Bricaud, A.; Ras, J. Optical properties of the "clearest" natural waters. Limnol. Oceanogr. 2000, 52, 217-229.

75. Maritorena, S.; Morel, A.; Gentili, B. Determination of the fluorescence quantum yield by oceanic phytoplankton in their natural habitat. Appl. Opt. 2000, 39, 6725-6737.

76. Zacharias, M.; Niemann, O.; Borstad, G. An assessment and classification of a multispectral bandset for the remote sensing of intertidal seaweeds. Canad.J. Remote Sens. 1992, 18, 263-274.

77. Call, K.A.; Hardy, J.T.; Wallin, D.O. Coral reef habitat discrimination using multivariate spectral analysis and satellite remote sensing. Int. J. Remote Sens. 2003, 24, 2627-2639.

78. Dierssen, H.M.; Zimmerman, R.C.; Leathers, R.A.; Downes, T.V.; Davis, C.O.; Davis, C. Ocean color remote sensing of seagrass and bathymetry in the Bahamas Banks by high-resolution airborne imagery. Limnol. Oceanogr. 2003, 48, 444-455.

79. Kutser, T.; Vahtmäe, E.; Metsamaa, L. Spectral library of macroalgae and benthic substrates in Estonian coastal waters. Proc. Estonian. Acad. Sci. Biol. Ecol. 2006, 55, 329-340.

80. Andréfouët, S.; Muller-Karger, F.E.; Hochberg, E.J.; Hu, C.; Carder, K.L. Change detection in shallow coral reef environments using Landsat 7 ETM+ data. Remote Sens. Environ. 2001, 78, 150-162.

81. Hochberg, E.; Atkinson, M. Capabilities of remote sensors to classify coral,algae and sand as pure and mixed spectra. Remote Sens. Environ. 2003, 85, 174-189.

82. Louchard, E.M.; Reid, R.P.; Stephens, F.C.; Davis, C.O.; Leathers, R.A.; Downes, T.V. Optical remote sensing of benthic habitats and bathymetry in coastal environments at Lee Stocking Island, Bahamas: A comparative spectral classification approach. Limnol. Oceanogr. 2003, 48, 511-521.

83. Thorhaug, A.; Richardson, A.D.; Berlyn, G.P. Spectral reflectance of the seagrasses: Thalassia testudinum, Halodule wrightii, Syringodium filiforme and five marine algae. Int. J. Remote Sens. 2007, 28, 1487-1501.

84. Snodderly, D.M.; Brown, P.K.; Delori, F.C.; Auran, J.D. The Macular Pigment. I. Absorbance spectra, localization, and discrimination from other yellow pigments in primate retinas. Microspectrophotometry 1983, 6, 660-673.

85. Gausman, H.W. Visible light reflectance, transmittance, and absorptance of differently pigmented cotton leaves. Remote Sens. Environ. 1982, 13, 233-238.

86. Richards, J.A. Remote Sensing Digital Image Analysis; Springer-Verlag: Berlin, Germany, 1999.

87. Conger, C.L.; Hochberg, E.J.; Fletcher, C.H.; Atkinson, M.J. Decorrelating remote sensing color bands from bathymetry in optically shallow waters. IEEE Trans. Geosci. Remote Sens. 2006, 44, 1655-1600.

88. Tassan, S. Modified Lyzenga's method for macroalgae detection in water with non-uniform composition. Int. J. Remote Sens. 1996, 17, 1601-1607

89. Purkis, S.J. A "Reef-Up" approach to classifying coral habitats from IKONOS imagery. IEEE Trans. Geosci. Remote Sens. 2005, 43, 1375-1390.

90. Mumby, P.J.; Edwards, A.J. Mapping marine environments with IKONOS imagery: Enhanced spatial resolution can deliver greater thematic accuracy. Remote Sens. Environ. 2002, 82, 248-257. 
91. Richardson, A.D.; Reeves, J.B.; Gregoire, T.G. Multivariate analyses of Visible/Near Infrared (VIS/NIR) absorbance spectra reveal underlying spectral differences among dried, ground conifer needle samples from different growth environments. New Phytologist 2004, 161, 291-301.

92. Glover, F.; Taillard, E.; de Werra, D. A user's guide to tabu search. Ann. Oper. Res. 1993, 41, 3-28.

93. Mumby, P.J.; Green, E.P.; Edwards, A.J.; Clark, C.D. The cost-effectiveness of remote sensing for tropical coastal resources assessment and management. J. Environ. Manag. 1999, 55, 157-166.

94. Strittholt, J.R.; Frost, P.A. Determining Abundance and Distribution of Eelgrass (Zostera marina) in Tillamook Bay Estuary, Oregon Using Multispectral Airborne Imagery; Tillamook Bay National Estuary Project: Garibaldi, OR, USA, 1996.

95. Johannessen, S.; Macdonald, R. Effects of local and global change on an inland sea: The Strait of Georgia, British Columbia, Canada. Climate Res. 2009, 40, 1-21.

96. Roelfsema, C.M.; Phinn, S.R.; Udy, N.; Maxwell, P. An integrated field and remote sensing approach for mapping seagrass cover, Moreton Bay, Australia. J. Spatial Sci. 2009, 54, 45-62.

97. Pe'eri, S.; Morrison, J.R.; Short, F.; Mathieson, A.; Brook, A.; Trowbridge, P. Macroalgae and Eelgrass Mapping in Great Bay Estuary Using AISA Hyperspectral Imagery; A Final Report to The New Hampshire Estuaries Project; The New Hampshire Estuaries Project: Durham, NH, USA, 2008; p. 148. Available online: http://www.prep.unh.edu/resources/pdf/ macroalgae_and_eelgrass-unh-09.pdf (accessed on 16 October 2010).

(C) 2011 by the authors; licensee MDPI, Basel, Switzerland. This article is an open access article distributed under the terms and conditions of the Creative Commons Attribution license (http://creativecommons.org/licenses/by/3.0/). 